\title{
A review of postpartum care education and care interventions in Iran
}

\author{
Sakineh Nazari ${ }^{1}$, Sepideh Hajian ${ }^{2}$, Zohreh Abasi ${ }^{3}$, HamidAlavi Majd ${ }^{4}$ \\ 1. Ph.D. student Reproductive Health, Student Research Committee, School of Nursing and Midwifery, Shahid Beheshti \\ University of Medical Sciences, Tehran, Iran. ORCID ID: 0000-0003-2290-0643. \\ 2. Associate Professor, Department of Midwifery and Reproductive Health, School of Nursing and Midwifery, Shahid \\ Beheshti University of Medical Sciences, Tehran, Iran., (Corresponding Author), Tel: +98-2188202512, Email: \\ s.hajian@sbmu.ac.ir. ORCID ID: 0000-0002-3368-0036. \\ 3. Assistant Professor, Department of Midwifery, School of Medicine, North Khorasan University of Medical Sciences, \\ bojnurd, Iran., ORCID ID: 0000-0002-7752-0587. \\ 4. Professor, Department of Biostatistics, School of Allied Medical Sciences, Shahid Beheshti University of Medical \\ Sciences, Tehran, Iran. ORCID ID: 0000-0001-7772-2923.
}

\begin{abstract}
Background and Aim: Postpartum period can be considered one of the most sensitive life stages. Special care is provided in different countries. The aim of this study was to evaluate postpartum care and educational programs in Iran.

Materials and Methods: Data were collected by searching, Scientific Information Dtabase, IranMedex, Magiran, Cochrane Library, PubMed, Google Scholar, Web of Science, Scopus databases. We used keywords of postpartum period, clinical trial, program, education, care, intervention, and also their Persian equivalents to search articles in Persian sources from 2009 to 2019. Then, the titles and abstracts of the articles were evaluated by using CONSORT and Jadad Check List. Finally 49 articles were reviewed.

Results: Interventions were performed in eight domains of home care, postpartum support, health promotion theory, physical training, counseling, e-learning, face - to - face educations, group educations. The variables in our study included quality of life, postpartum depression, breastfeeding, satisfaction with quality of care, fatigue and sleep, and the performance of mothers.
\end{abstract}

Conclusion: Improvement of the quality of postpartum care needs enriched country care programs on the basis of successful evidence obtained from existing studies in the country such as home visiting and telephone follow up calls for mothers during the sensitive postpartum period.

Keywords: Postpartum period, Clinical trial, Program, Education, Care

Received: Dec 21, $2019 \quad$ Accepted: Apr 7, 2021

How to cite the article: Nazari, Sepideh Hajian, Zohreh Abasi, HamidAlavi Majd. A review of postpartum care education and care interventions in Irans. SJKU. 2021;26(3):86-104.

Copyright @ 2018 the Author (s). Published by Kurdistan University of Medical Sciences. This is an open access article distributed under the terms of the Creative Commons Attribution-Non-Commercial License 4.0 (CCBYNC), where it is permissible to download, share, remix, transform, and buildup the work provided it is properly cited. The work cannot be used commercially without permission from the journal 


\section{مرورى بر مداخلات آموزشى و مر اقبتى بس از زايمان در ايران}

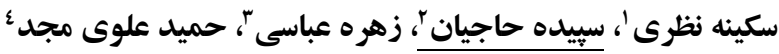

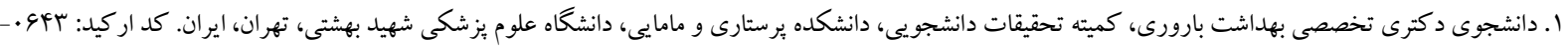
rrq...........

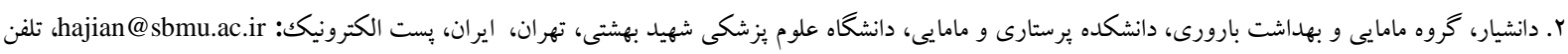
ثابت:

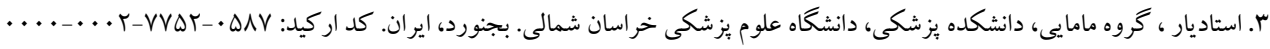

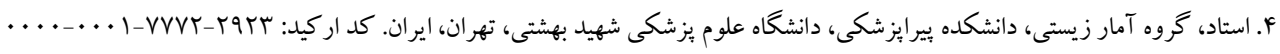

جكکטه

زمينه و هدف: دوره يُ از زايمان را مىتوان يكى از حساسترين مراحل زندگى به شمار آورد. در كشورهاى مختلف مر اقبتهاى ويزٔاى در نظر گر فته شده است، اين مطالعه با هدف بررسى برنامهاى مراقبتى و آموزشى بس از زايمان در ايران انجام شده است.

مواد و روشها: داده هاى اين يُزوهش با جستجو در بايكاههاى اطلاعاتى Scientific Information Database، Scopus و Web of Science ،Google Scholar ‘PubMed ،Cochrane Library ،Magiran ،IranMedex بدست آمد. براى جستجوى مقالات در منابع فارسى از كليد وازههاى مر تبط با موضوع، دوره بس از زايمان، دوره بعد از زايمان،

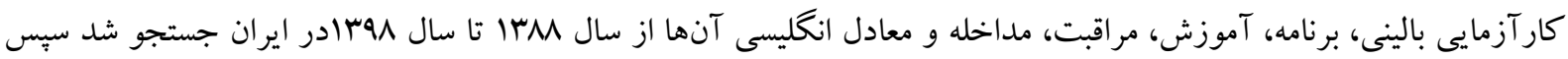

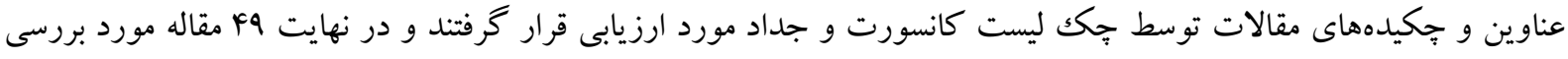
قرار گرفت. يافتهها: يافتها نشان داد ارائه مداخلات در هشت حيطه آموزشهاى مبتنى بر مراقبت در منزل، حمايت پِ إز زايمان، تئورىهاى

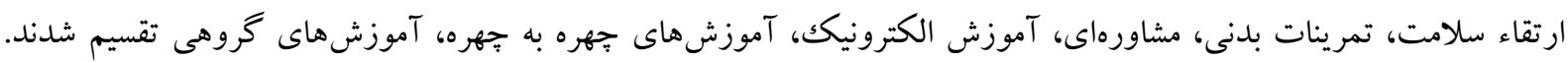

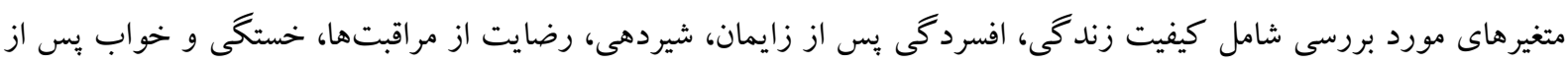
زايمان و عملكرد مادران بود. نتيجه كيرى: بهبود كيفيت مر اقبتهاى بس از زايمان نيازمند غنى تر شدن محتواى برنامه كشورى مبتنى بر شواهد موفق بود تحقيقات

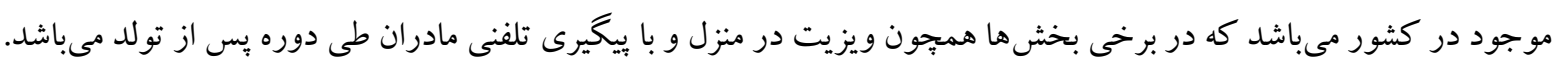
كلمات كليدى: دوره پِ از زايمان، مطالعه تجربى، برنامه، آموزش، مراقبت

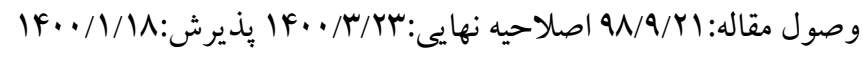


مختلف كيفيت ارائه خـدمات مناسـب نبـود بـه طـورى كهـ براساس مطالعه لومرو در حجين بيش از نيمسى از مراقبتهـا از كيفيت پايين برخوردار بودند(· •(1). بايســ در نظـر داشـت كـه اغلـب زنـان، زايمـان را در زمينـهـ

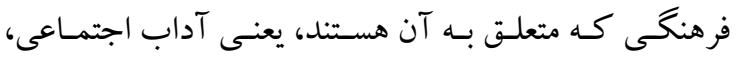

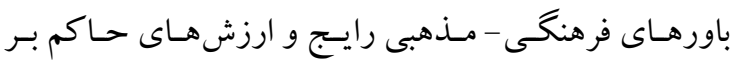

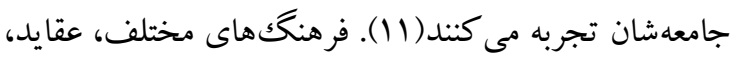

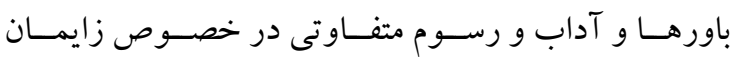
دارند(Y) بنابراين، مراقبتهاى بعد از زايمان علاوه بر ارتقاء

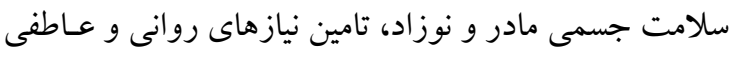

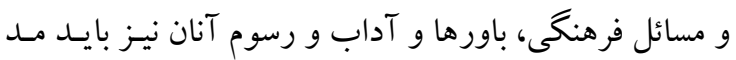

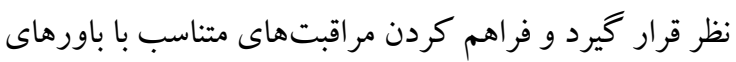

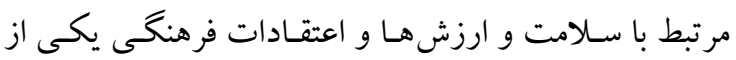
اهداف مراقبتهاى اين دوران است( آ).

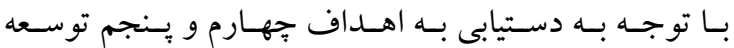

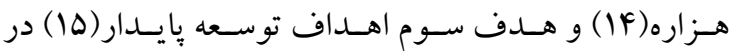
خصوص توجـه بـه سـلامت مـادران و كود كـان، و رويكرد ويزه سياستهاى كشورى در جهت افزايش نرخ بـارورى و يشيخيرى از بروز بيامدهاى ناخو استه و قابل اجتناب مادرى و

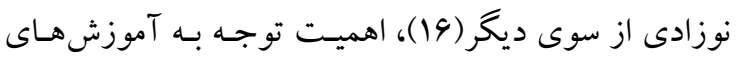
دوران يֶ از زايمان را بيش از يـيش نمايـان مىسـازد(IV).

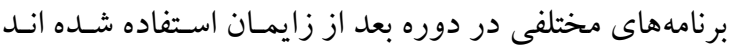
كه اين مطالعه با هدف بررسى برنامههاى مراقبتى و آموزشى ״ِ از زايمان انجام شده است تا براساس آن در تدوين ارائه بهترين برنامه مر اقبتى سلامت كامى برداشته شود.

\section{مواد و روش ها}

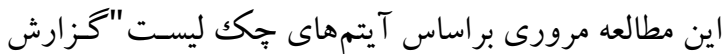
مـرور سيستماتيك و متآنـاليز (PRISMA) انجـام شـــ.

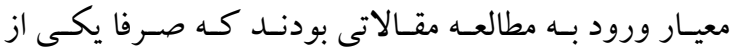

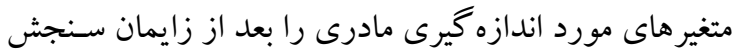
مى كردند، بدين دليل مطالعات كمى مداخلهاى در ايـران بـهـ بررسى برنامهها و آموزش ها و مداخلات و مر اقبتهاى دوره

\section{مقلمه}

دوره يـسـ از زايمـان از ديربــاز مــورد توجسهـ بــوده و در كشورهاى مختلف مر اقبتهاى ويزّاى بـراى ايـن دوران در نظر كرفته شده است( (1). اين دوره شامل حند هفته اول بـس

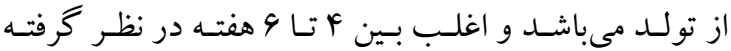
مىشـود(Y)، ايسن دوران را مىتسوان يكسى از حسـاس ترين

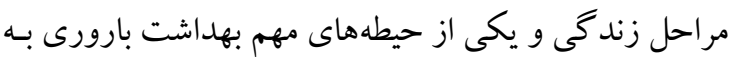

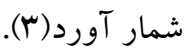
از آنجـا كـهـ در دوران بـاردارى و بعـــ از زايمـان تغييـرات

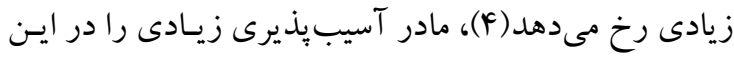

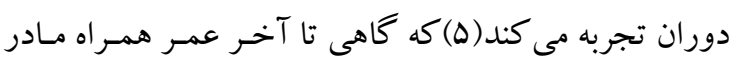

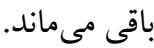
اهميت برنامهريزى و مراقبت صحيح در ايـن دوران هميشـه

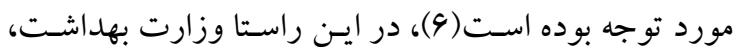

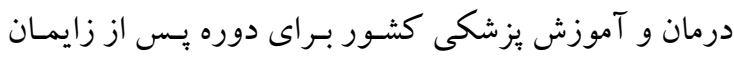
برنامسهاى را تــدوين نمـوده اسـت كـه شـامل سـهـ نوبــت مراقبتهاى دوره بس از زايمان براى مـادر در روزهـاى اول تا سوم(نوبت اول)، جهارده تا بانزده(نوبت دوم)، جهل و دو لماك

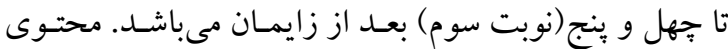

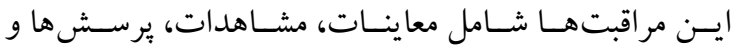

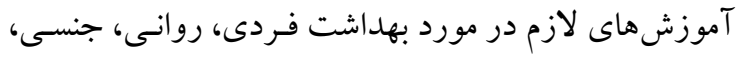
دهان و دندان، علائم خطر، شـكايتهاى شـايع، تغذيـه ايـن دوره و مكمل هاى دارويى، شيردهى، مشكلات و تداوم آن، مراقبت از نوزاد و تنظيم خانواده است. باوجود اين، متأسفانه مر اقبتهاى دوران بعـد از زايمـان بـا وجـود حسـاس بـودن، اغلب توسط مـراقبين سـلامت و ماماهـا در مقايسـه بـا دوران باردارى، جه به لحاظ كمى و جهه به لحاظ كيفى كمتر مـورد

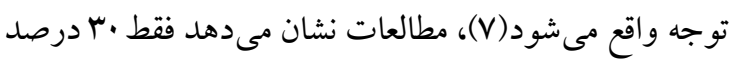

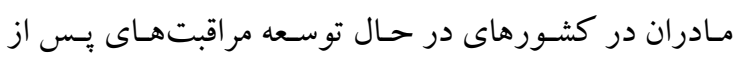

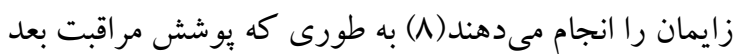

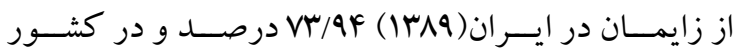

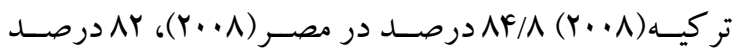
است(9). على رغم يوشش مناسب مراقبتهـا در كشـورهاى 
بود يكك امتياز تعلق مى گرفت و اگر تصادفى سازى بـه روش

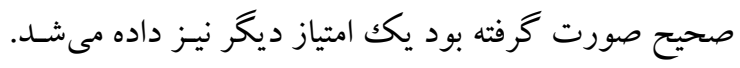

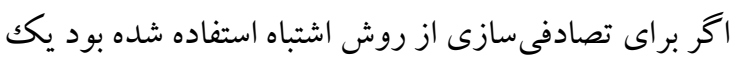

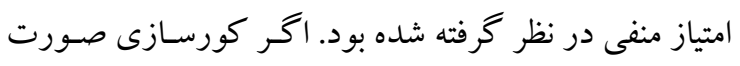

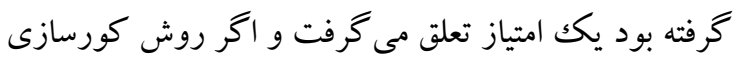

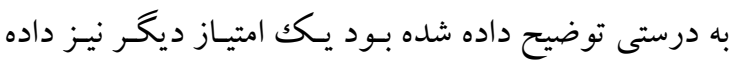
مى شد و در صورتى كه كورسازى صحيح نبود يـك امتيـاز

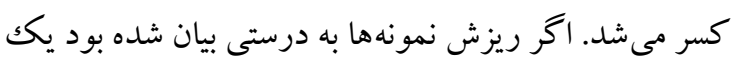

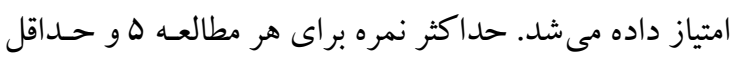

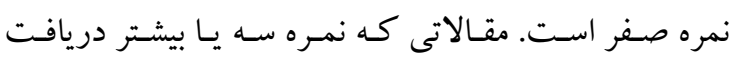

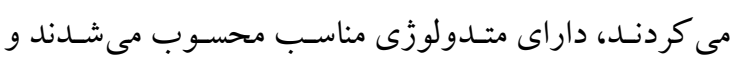

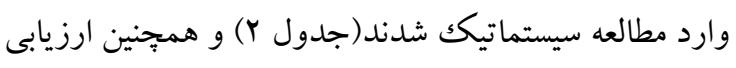

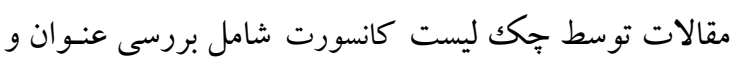

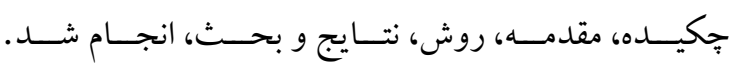

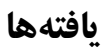

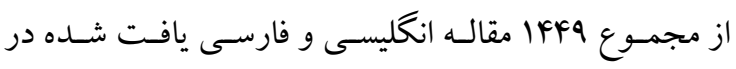

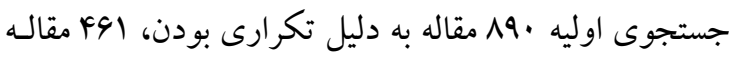
به دليل غير مرتبط بودن با اهداف بثروهش از مطالعه خـارج

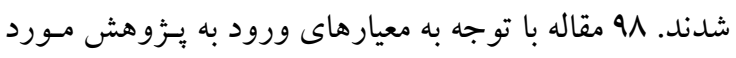

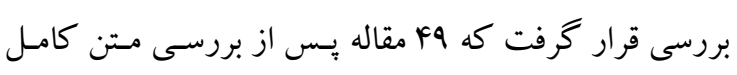

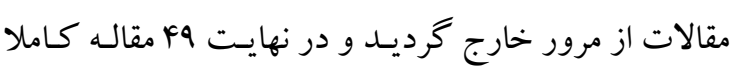

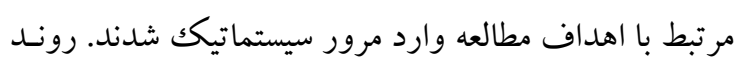
بررسى مقالات در فلوجارت ا خلاصه شده اند.

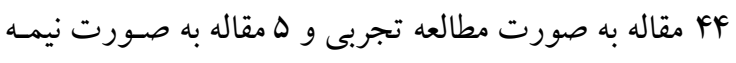

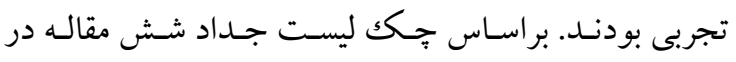

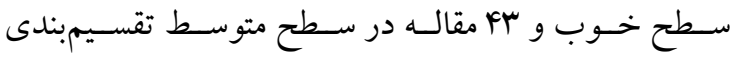

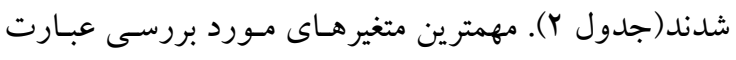

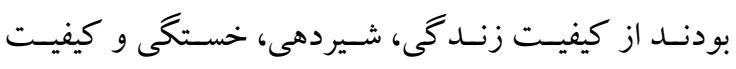

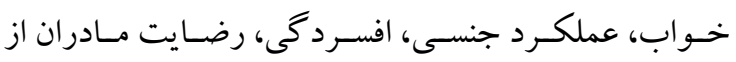

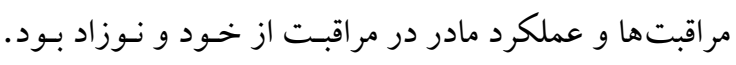

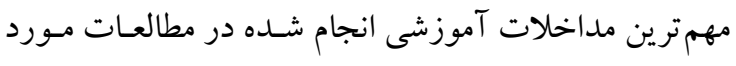

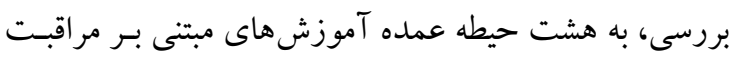

پِ از زايمان يرداخته بودند وارد اين مطالعه شدند. مقالاتى

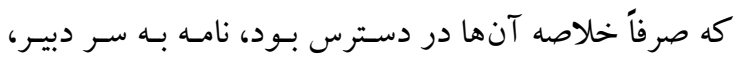

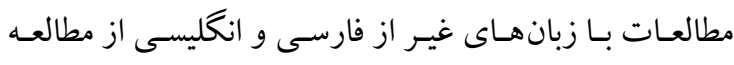
حذف شدند. در ايـن مطالعـه مـرور سيستماتيكك بـه منظور

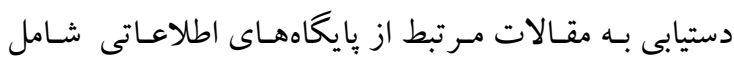
مركسز اطلاعـات علمسى ( Scientific Information

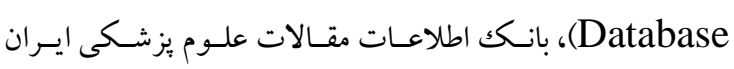

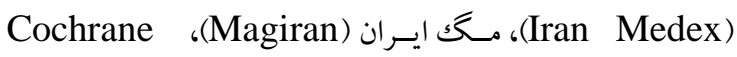
Web of ،Google Scholar ‘PubMed ،Library Scopus و استفاده شد. براى جستجوى مقـالات Science در منابع فارسى از كليد وازههاى دوره يس از زايمـان، دوره

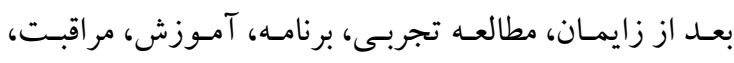

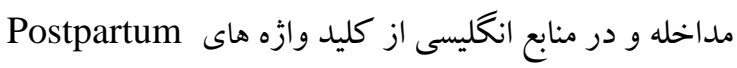
‘Puerperium intervention sprogram speriod Randomized Clinical ‘education ،Care spostnatal

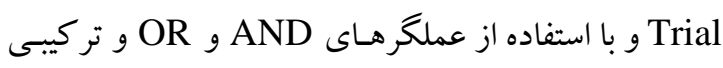

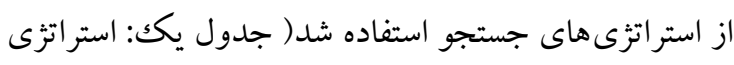

$$
\text { جستجو در پِاب مد) }
$$
مقالات در ب مرحله مورد بررسى قرار گر فتند: ابتدا نوع مقاله

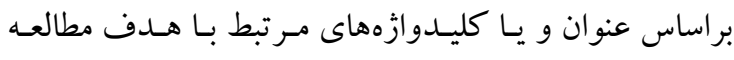

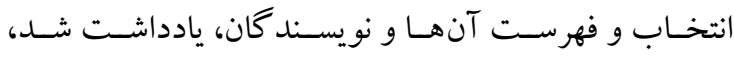

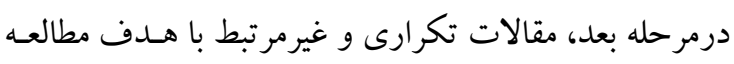

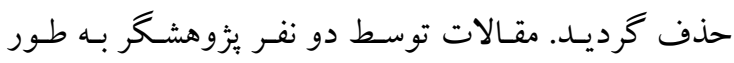

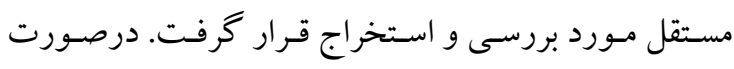

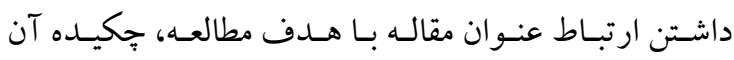

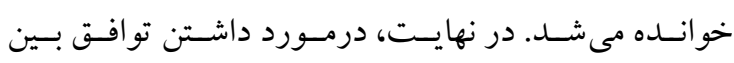

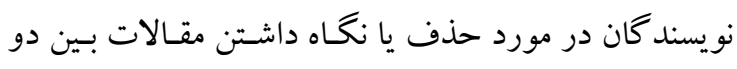

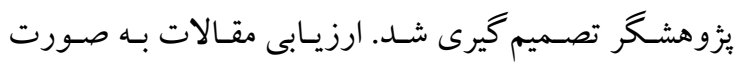

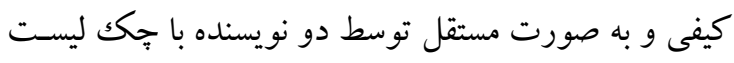

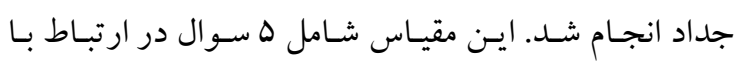
كار آزمـايى بـودن مطالعـه، روش تصادفى سـازى و احتمـال

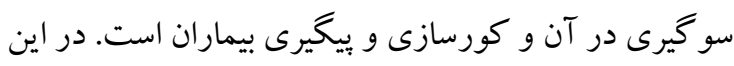

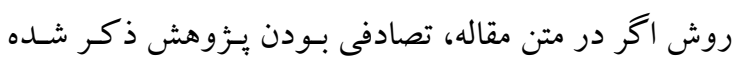


نتايج آنها باعث بهبود شيردهى و كاهش افسردگى بـس از

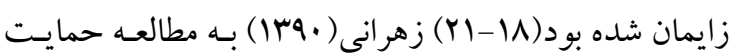

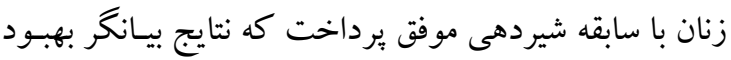

تغذيه انحصارى بود(Y) (Y).

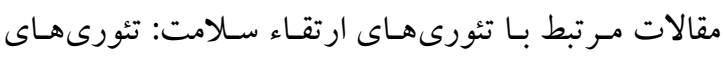

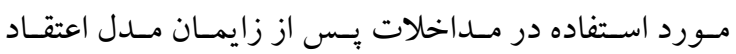

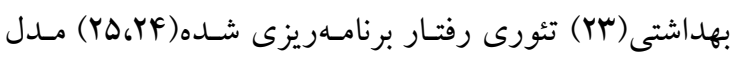

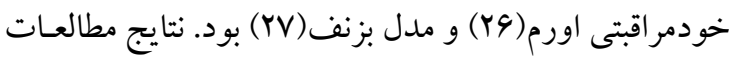

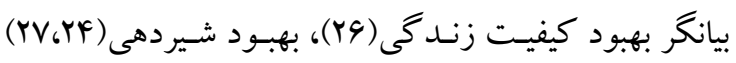

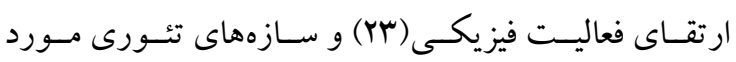

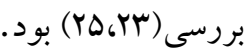
مقالات مبتنى بر آموزش تمرينـات بــنى بـى سـه مطالعه انجـام

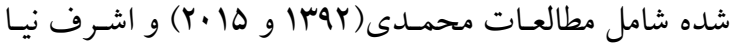
(Y.10) بود كه مطالعه اشرف نيـا و همكـاران نشـان داد كـه ورزش مى تواند بر خستخى و فعاليتهاى فيز يكى تاثير مثبت

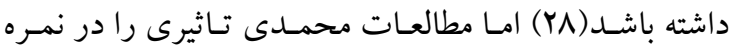
خستخى و افسردگى يس از زايمان كزارش نكردند(9)، ·r). مقالات مرتبط بر مداخلات مشاورهاى: مداخلات مشاورهاى

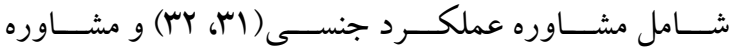

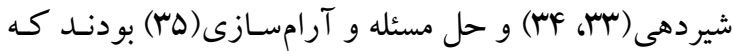

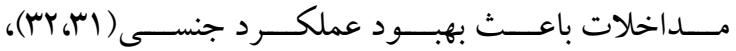

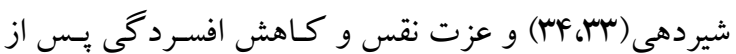

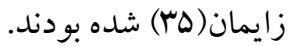
مقالات مبتنى بر آموزش الكترونيكك: آموزش الكترونيكك

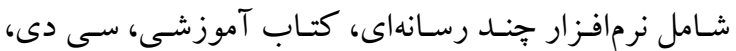

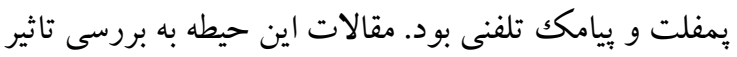

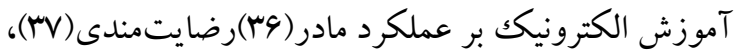

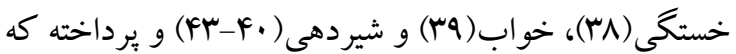
همخى باعث بهبود مشكلات مورد بررسى شده بودند

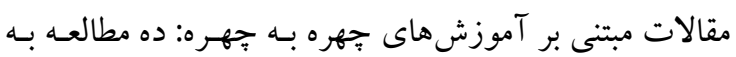

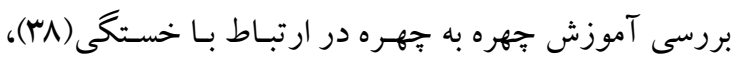

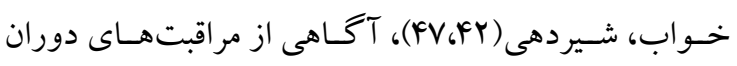

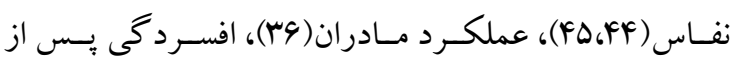

در منزل( (1 مقاله)، آموزش هاى مبتنى بر حمايتهاى بِ از زايمان( ال مقاله)، آموزشهاى مرتبط بـا تئورىهـاى ارتقـاء

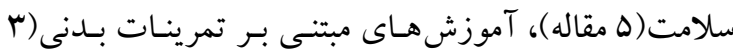

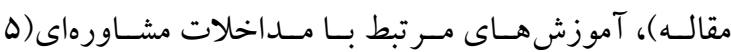
مداخله)، مداخلات مبتنى بر آموزش الكترونيك (9 مقاله)،

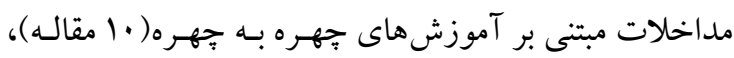

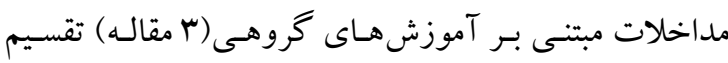

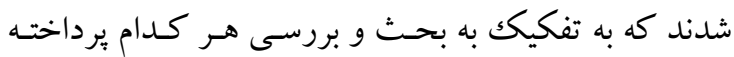
مىشود. آموزشهاى مبتنى بر مراقبت در منزل: بيشتر مطالعات مرتبط با مراقبت در منزل همان مراقبت يس از زايمان برنامـه ادغـام يافته وزارت بهداشت مىباشد اما مطالعه شمشيرى ميلانى بـا تلفيق دستورالعمل كشـورى و برنامـه تطبيقى بـا كشـورهاى

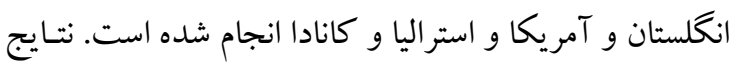

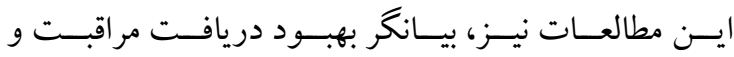
رضايتمندى مادران(1) بهبود عملكرد مادران در مر اقبت از

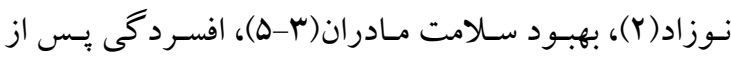

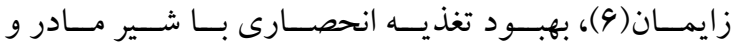

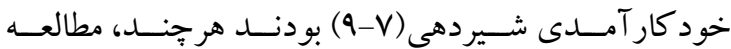
شمشيرى ميلانى(Y. V نشان داد كه مراقبت در منزل در دو ماه بعد از زايمـان باعـث بهبـود يبوسـت و هموروئيـد نشـده بود( •(1)، همجينين مطالعه ميرمولايى و همكاران نيز تاثير قابل مشاهدهاى را نسبت به مراقبت هاى معمول، در بهبود كيفيت زندگى يس از زايمان با اين روش مراقبتى تاييد نكرد(1). آموزشهاى مبتنى بر حمايتهاى بِ از زايمان: سه مطالعهـ

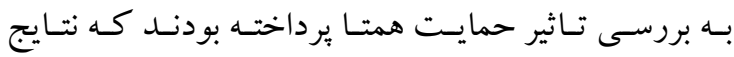

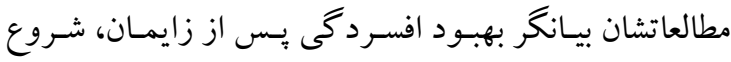
زودرس اولين تغذيـه بـا شـير مـادر بعـد از زايمـان و بهبـود

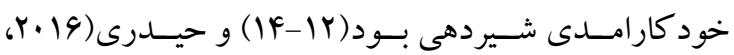

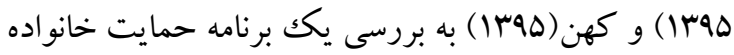
محور برداخته بودند كه باعث بهبود تغذيه انحصارى با شير مادر، توانمندى شيردهى و عملكرد مـادران شـده بـود(ها (1-

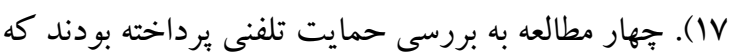




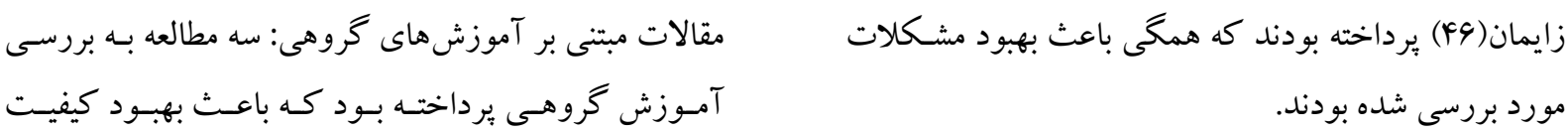

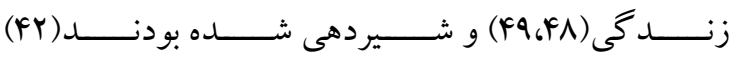

جدول ا: استراتخى جستجو در پياب مد

\#1" postpartum” in mesh

\#2 Period, Postpartum, Postpartum, Women, Postpartum, ,Postpartum Women Puerperium,

\#3Combination \#1 AND \#2: ("postpartum" OR (Period AND Postpartum) OR(Women AND Postpartum) OR (Puerperium)

\#4 postnatal care in mesh

\#5 Care, Postnatal, Postpartum Care, Care, Postpartum, Postpartum Programs, Postpartum Program,Program, Postpartum, Programs, Postpartum

\#6 Combination \#4 and \#5: ("postnatal care" OR(Care AND Postnatal) OR "Postpartum Care"OR "Care AND Postpartum" OR "Program AND Postpartum “

\#7 Combination \#3 and \#6

\#8 2009:2019[dp] and iran

\#9 Combination \#7 and \#8

("postpartum" OR (Period and Postpartum) OR(Women AND Postpartum) OR (Puerperium, ("postnatal care" OR(Care AND Postnatal) OR "Postpartum Care" OR "Care AND Postpartum" OR "Program AND Postpartum “ AND 2009:2019/dp] and iran)

\#10("postpartum"Itiab] OR (Period AND Postpartum) [tiab] OR(Women AND Postpartum) [tiab] OR (Puerperium[tiab], ("postnatal care" OR(Care AND Postnatal) [tiab] OR "Postpartum Care"[tiab] OR “Care AND Postpartum"[tiab] OR “Program AND Postpartum "[tiab] AND 2009:2019[dp] and iran[tiab])

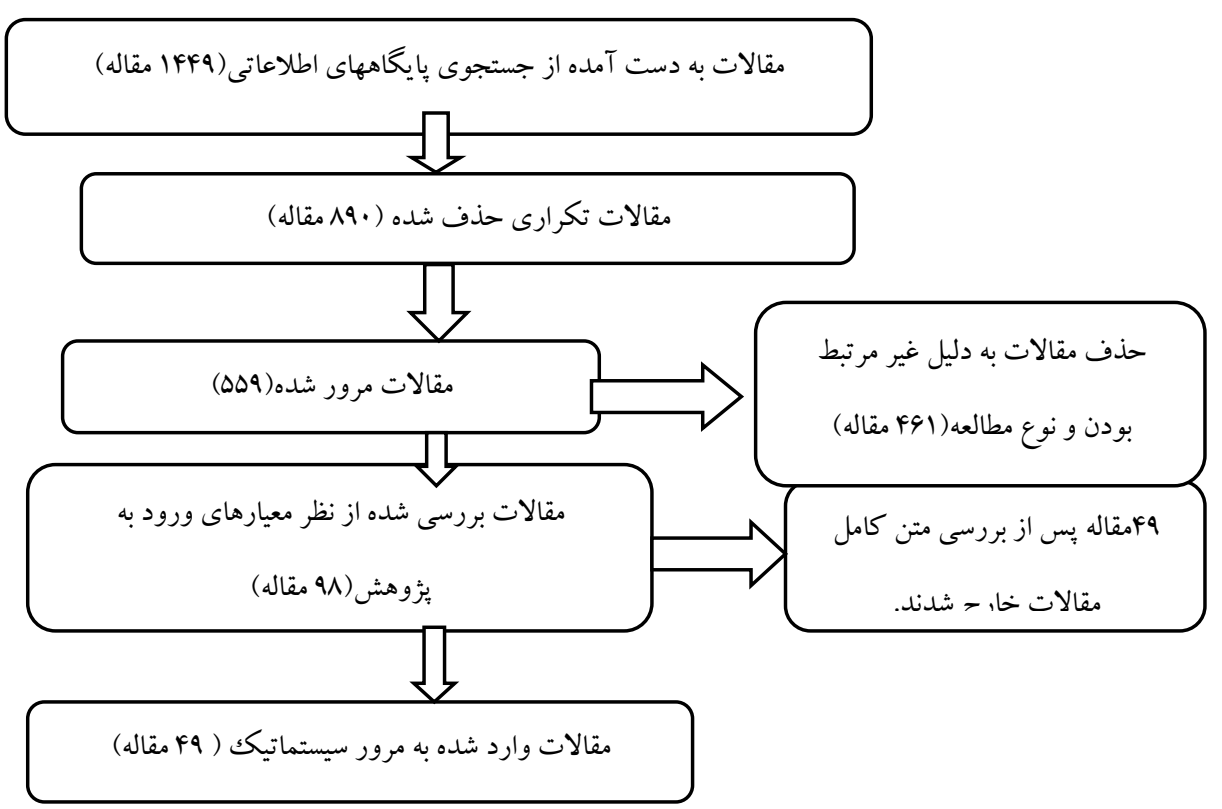

فلوجارت يكك: فلوجارت ورود مطالعات به مرور سيستماتيك 


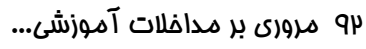

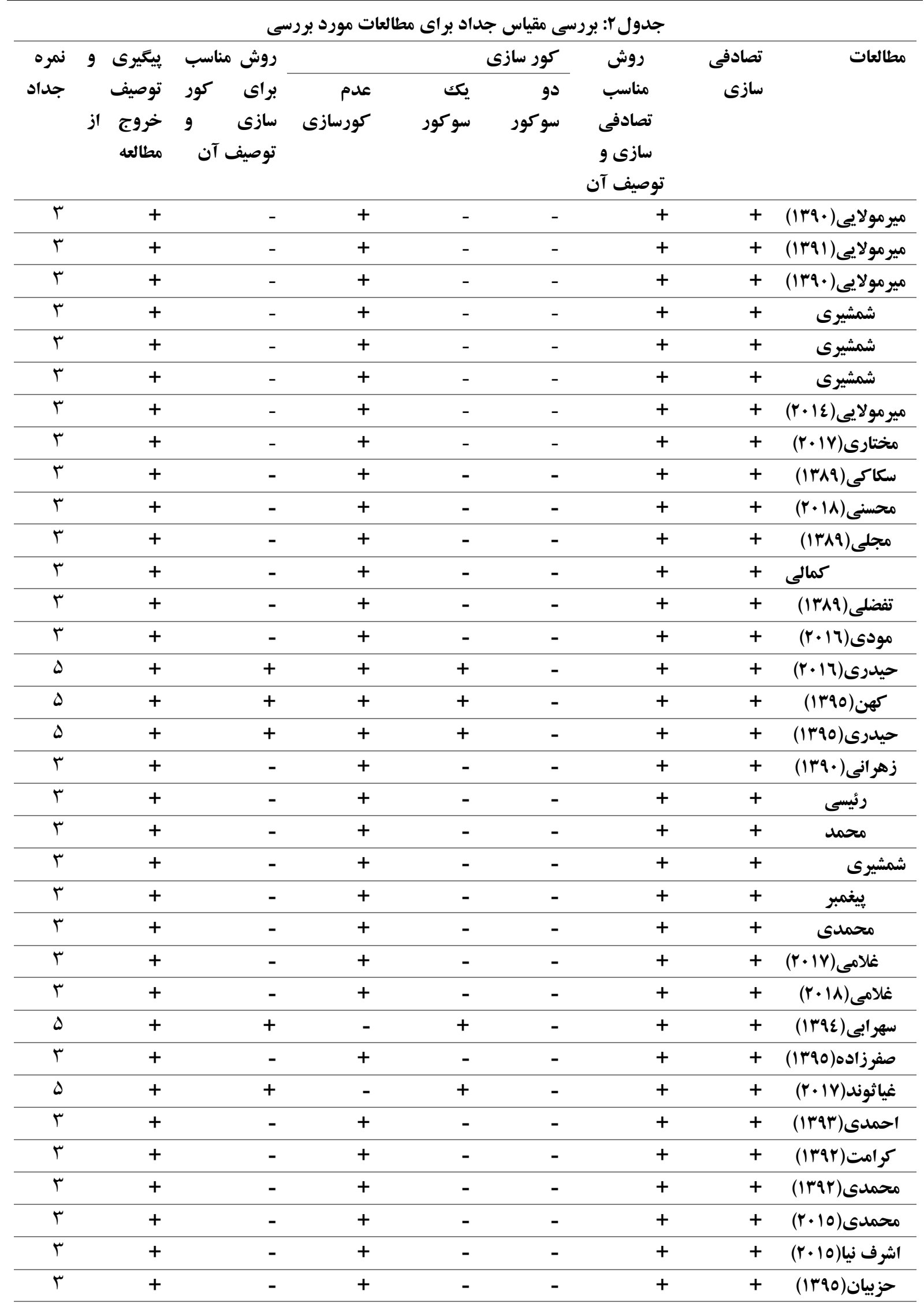




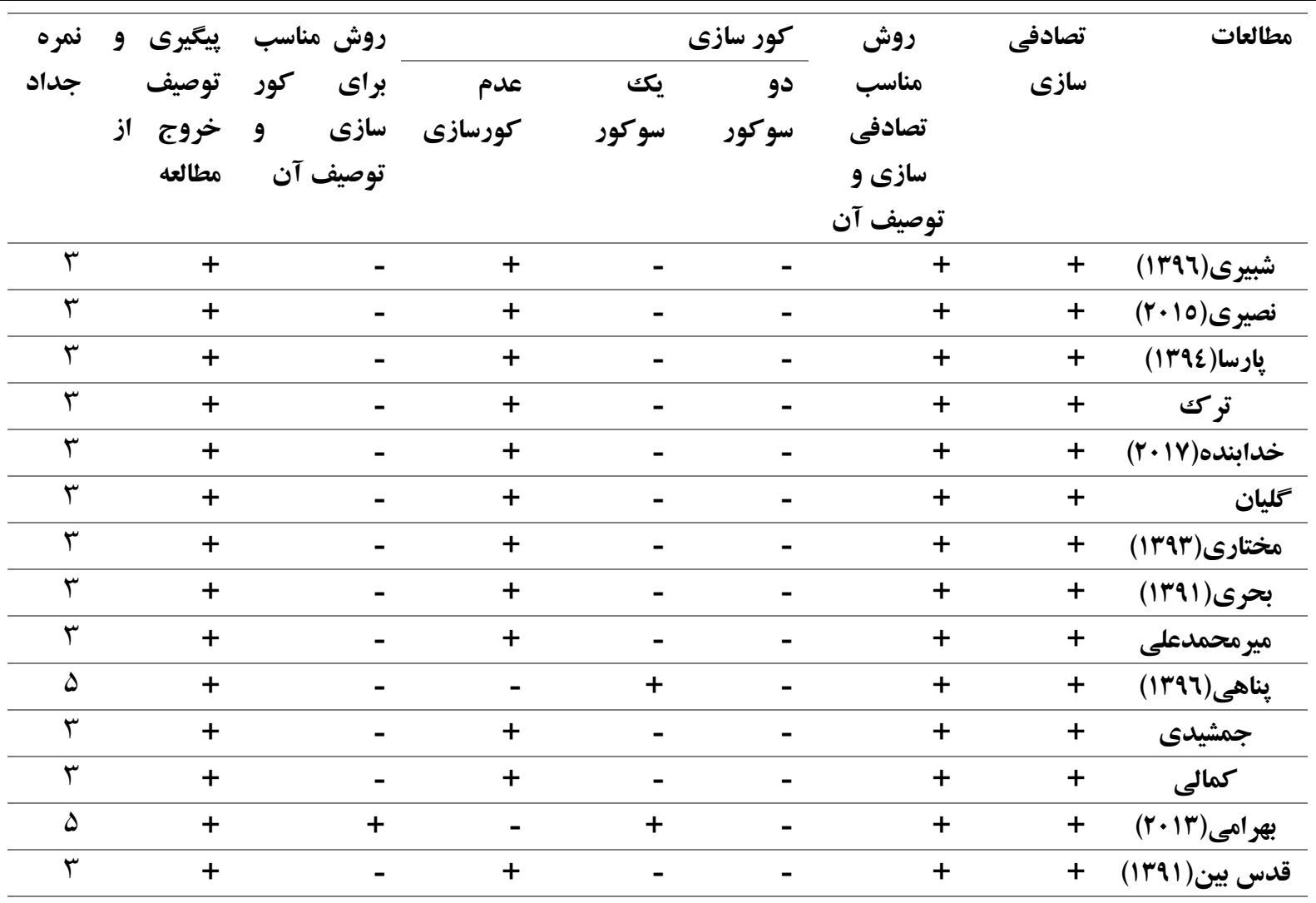

جدول شماره rا. مشخصات كلى مقالات مورد بر رسى در مطالعه حاضر

\begin{tabular}{|c|c|c|c|c|c|}
\hline يافته ها & روش كار & حجم نمونه & عنوان يخوهش & نو نام & .9 \\
\hline مندى مادود رضايت & ارائه مراقبت هاى بِ از زايمان در منزل & 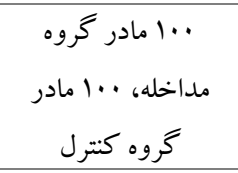 & 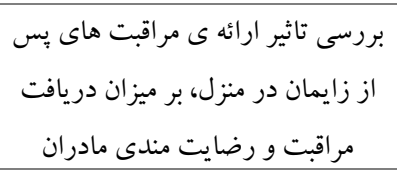 & مولايى ·ara & 1 \\
\hline 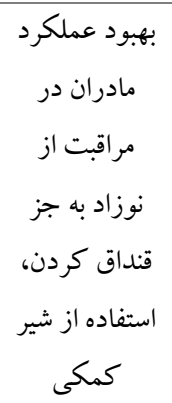 & ارائه مراقبت هاى بِ از زايمان در منزل & 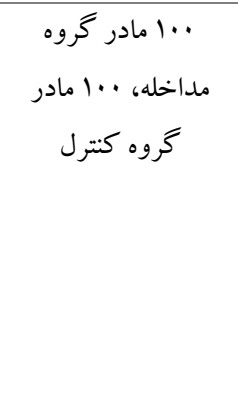 & 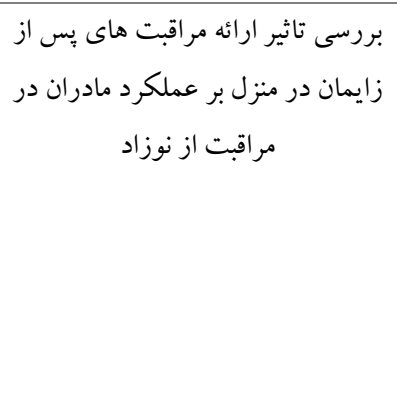 & اوير مولايى & $r$ \\
\hline كيفيت زندمى بهـود & روائه مراقبت هاى بس از زايمان در منزل & 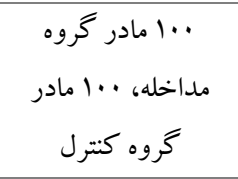 & 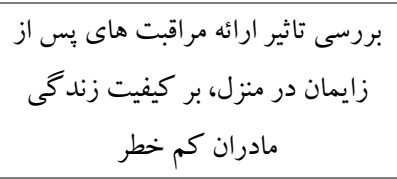 & ميرمولايى. & $r$ \\
\hline ازبوبود استفاده & ار بائه مراقبت هاى بِ از زايمان در منزل & 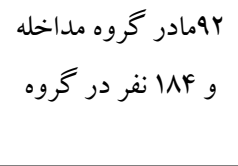 & 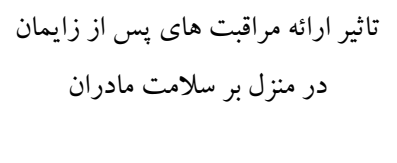 & 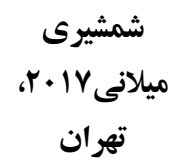 & $\varepsilon$ \\
\hline
\end{tabular}




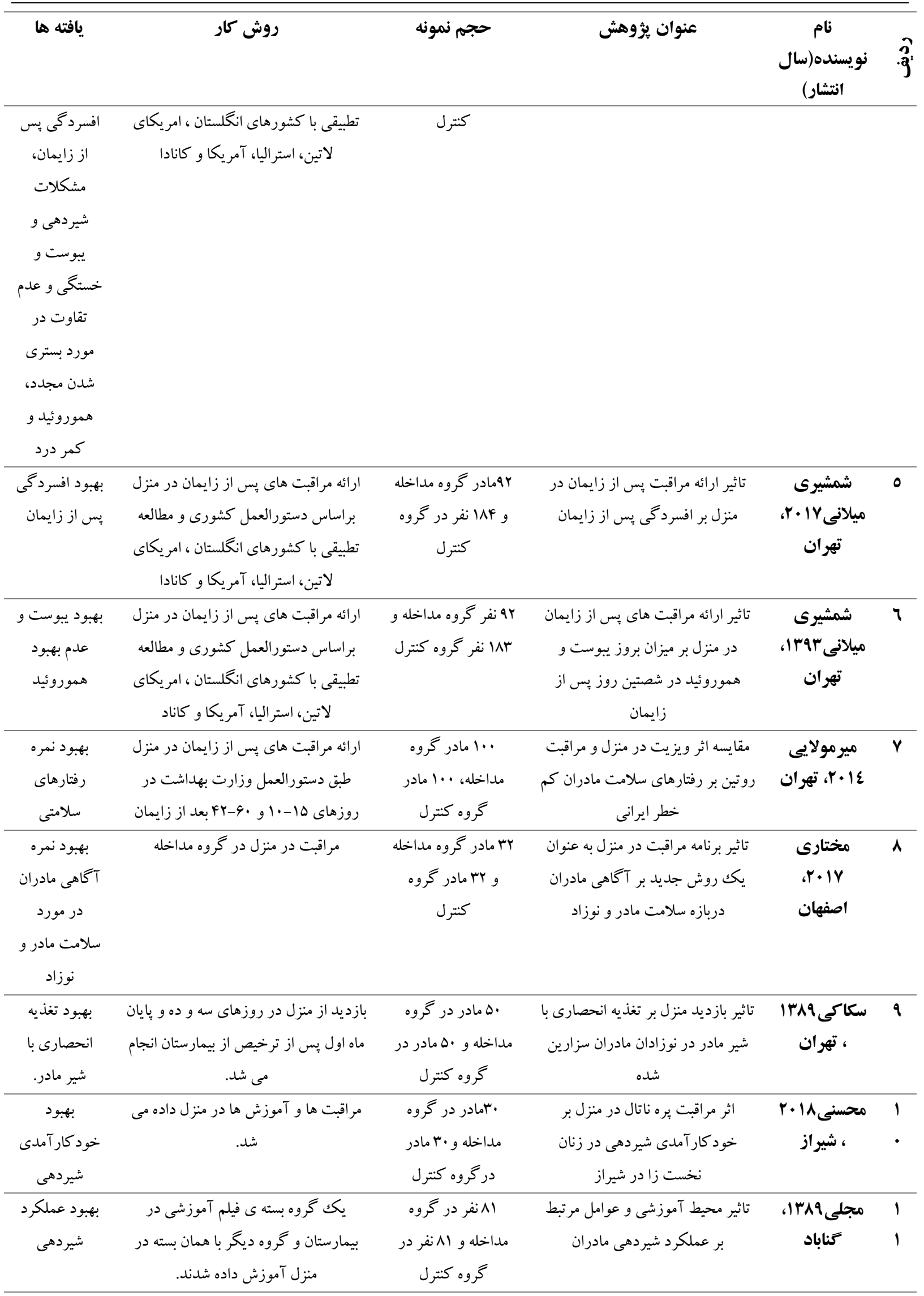




\begin{tabular}{|c|c|c|c|c|c|}
\hline يافته ها & روش كار & 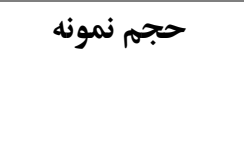 & 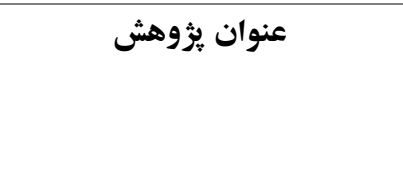 & نويسنده(سال & . \\
\hline 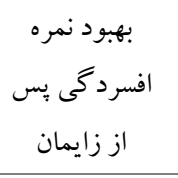 & حمايت تلفنى همتا از سه ماهه سوم & 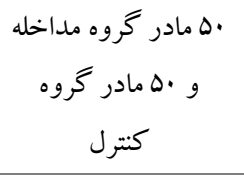 & زائير حمايت همتا بر افسردگى بس از & 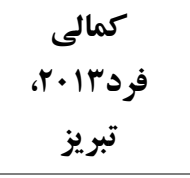 & $\begin{array}{l}1 \\
r\end{array}$ \\
\hline زمام تفاوت در شرو شروع & 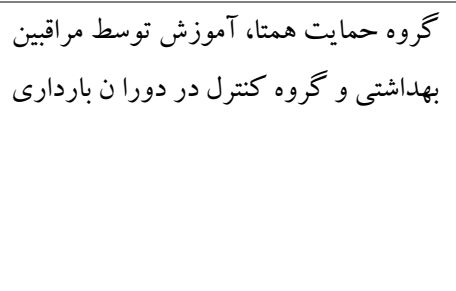 & 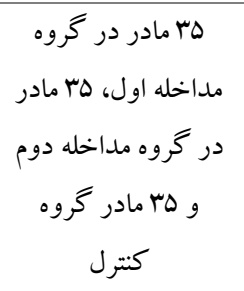 & 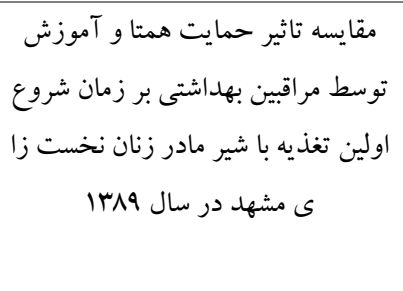 & تفضلى & $\begin{array}{l}1 \\
r\end{array}$ \\
\hline خود كارامدى شيود نمره & بروه حمايت همتا، آموزش توسط مراقبين & 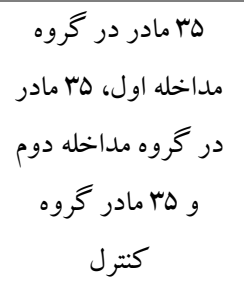 & 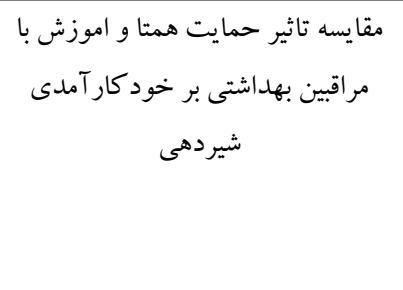 & 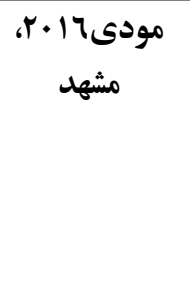 & $\begin{array}{l}1 \\
\varepsilon\end{array}$ \\
\hline انجبود تغذيه & 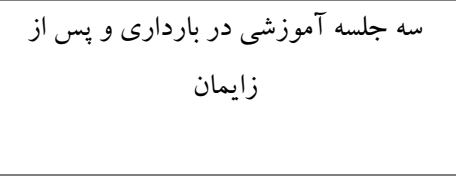 & 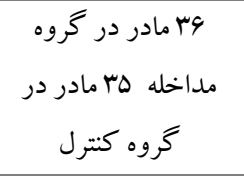 & 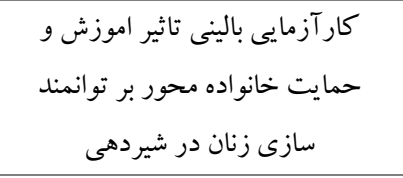 & حيدرى & $\begin{array}{l}1 \\
0\end{array}$ \\
\hline 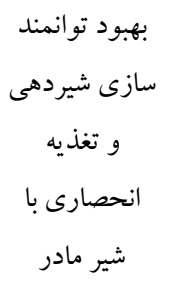 & سه جلسه آموزشى در باردارى و يس از & مداخله هب مادر در كروه دره & 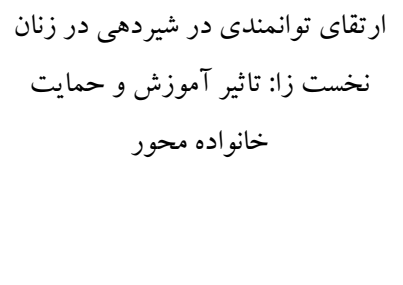 & كهن & $\begin{array}{l}1 \\
7\end{array}$ \\
\hline بهبود نمرات & 9 جلسه دو ساعته در دوران باردارى & 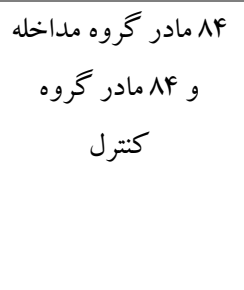 & 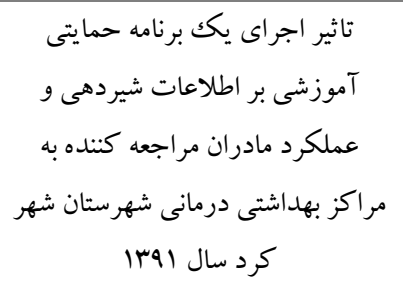 & حوبدر، شهر & $\begin{array}{l}1 \\
v\end{array}$ \\
\hline انحصارى با بهود تغذيه & 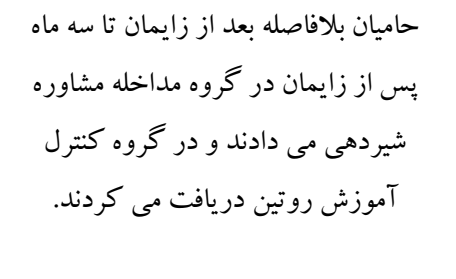 & 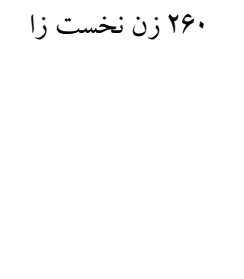 & 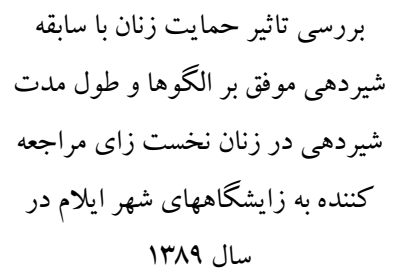 & 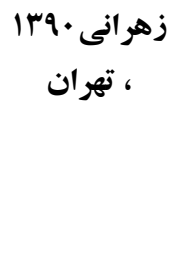 & $\begin{array}{l}1 \\
1\end{array}$ \\
\hline انحصارى بال & 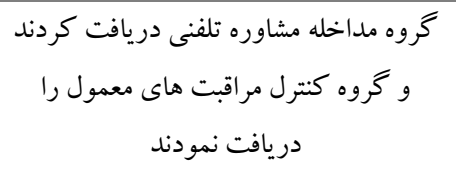 & 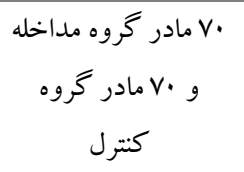 & مدت شير مشاوره تلفنى بر تداوم و طول & 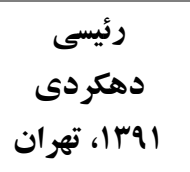 & $\begin{array}{l}1 \\
9\end{array}$ \\
\hline 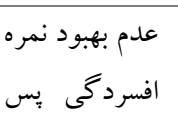 & و حمايت تلفنى دو بار در هفته در هفته اول & 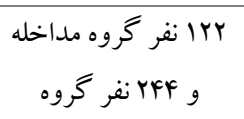 & 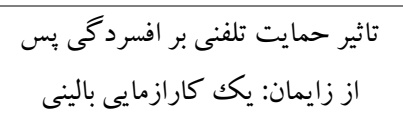 & هحمدعليز اد • ماد، تبريز & r \\
\hline
\end{tabular}


94 درورى بر دمافلات آهوزشى....

\begin{tabular}{|c|c|c|c|c|c|}
\hline يافته ها & روش كار & حجم نمونه & 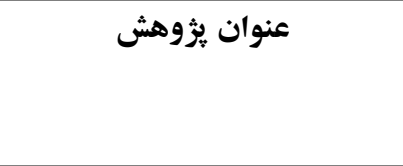 & نامنده(سال & \\
\hline از زايمان & زايمان & كنترل & & & \\
\hline 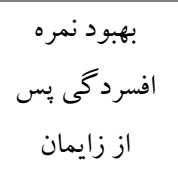 & دريافت حمايت تلفنى ب-Y بار در هفته به & 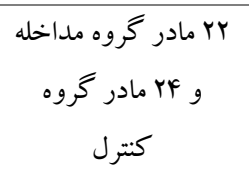 & تاثير حمايت تلفنى بر افسردگى بس زايس & 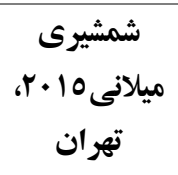 & $\begin{array}{l}r \\
1\end{array}$ \\
\hline 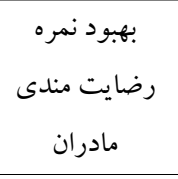 & هفته Y تا و هفته اي حمايت تلفنى هفته اول دوبار و & 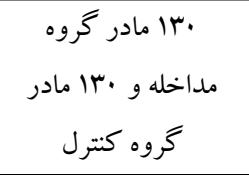 & 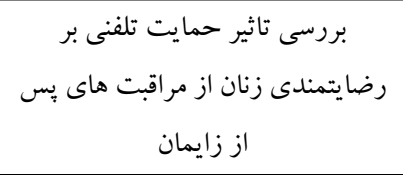 & دوستيغمبر & $\begin{array}{c}1 \\
r\end{array}$ \\
\hline هاع مدبود سازه & 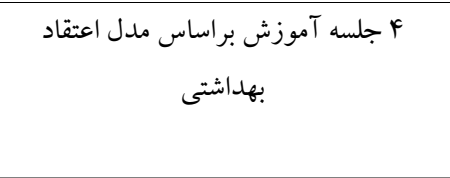 & $\begin{array}{l}\text { 94نفر گروه مداخله و } 9 \text { وائفر گروه كنترل }\end{array}$ & 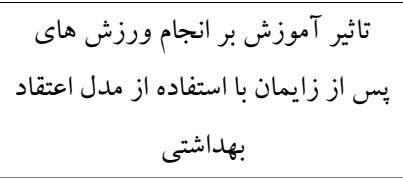 & زاده صوَrا، & 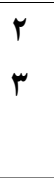 \\
\hline كيفيت زندبود نمره & 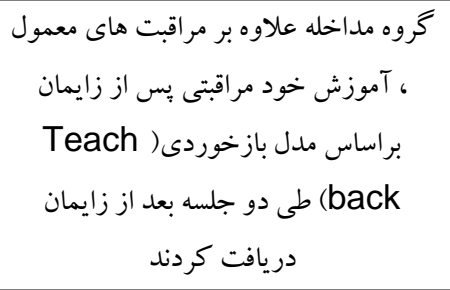 & 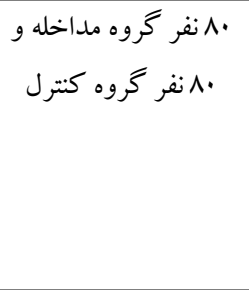 & 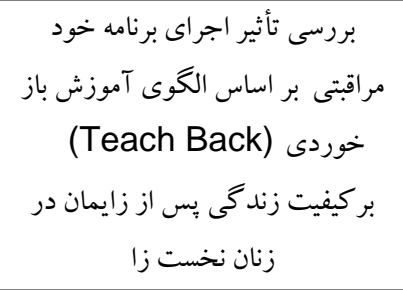 & ، غياثوندلا • درو شهر & $\begin{array}{l}r \\
\varepsilon\end{array}$ \\
\hline 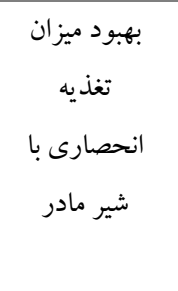 & سه جلسه اموزش در باردارى و بس از & 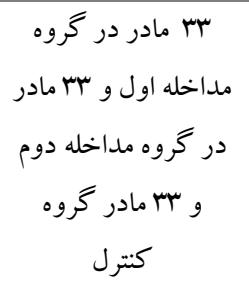 & 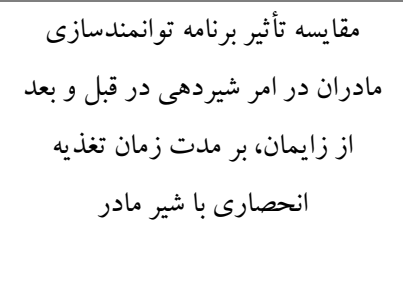 & يزدان عبد اصفها، & $\begin{array}{l}r \\
0\end{array}$ \\
\hline شير بهود نمره & آموزش براساس تئورى رفتار برنامه ريزى & 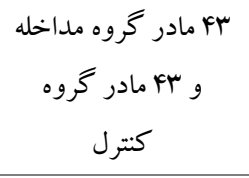 & تاثير برنامه آموزش براساس تئورى & احوس احمدى تهر ان & $\begin{array}{l}r \\
7\end{array}$ \\
\hline رئر ريود سازه & آموزش براساس رفتار برنامه ريزى شده & 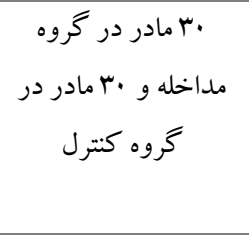 & 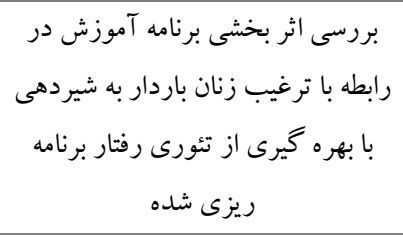 & كرامت شوبا & $\begin{array}{l}r \\
r\end{array}$ \\
\hline خدمَ بهبود نمره بس از & ورزش دوران باردارى و پس از زايمان & 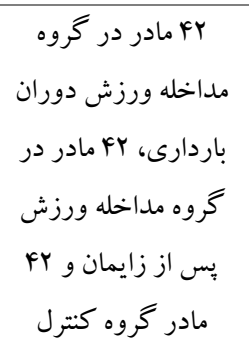 & تاثير ورزش بر خستخى بعد از زايمان: & 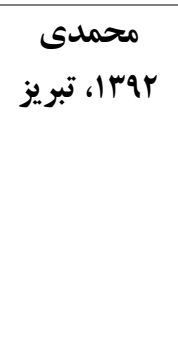 & $\begin{array}{l}r \\
\Lambda\end{array}$ \\
\hline 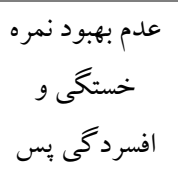 & ورزش دوران باردارى و يس از زايمان & 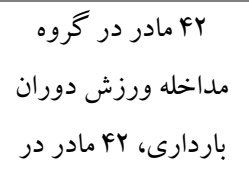 & تاثير ورزش در منزل بر خستكى و & 10 محمدى +r تبريز & $\begin{array}{l}r \\
q\end{array}$ \\
\hline
\end{tabular}




\begin{tabular}{|c|c|c|c|c|c|}
\hline يافته ها & روش كار & حجم نمونه & 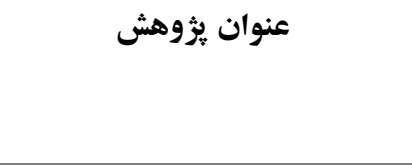 & 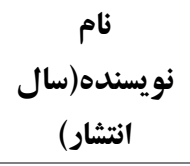 & . \\
\hline از زايمان & & 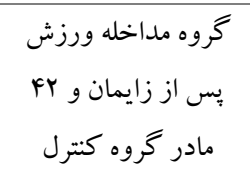 & & & \\
\hline خهبود نمره & زايمان ينج بار در هفته به مدت هلاتس هشت هاعت بعد از هفته & 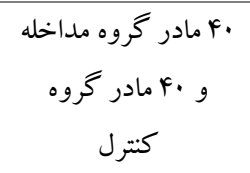 & بررسى ورزش بيلاتس بر خستگى از زايمان & رفياه • اشرف، & r \\
\hline جبهود عملكرد & 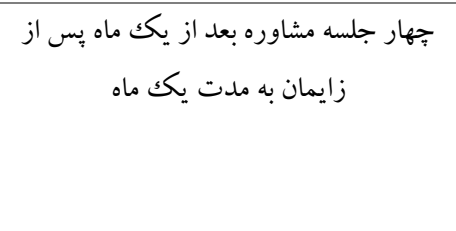 & 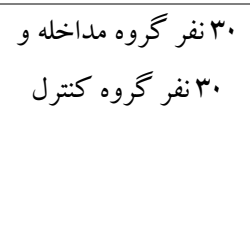 & 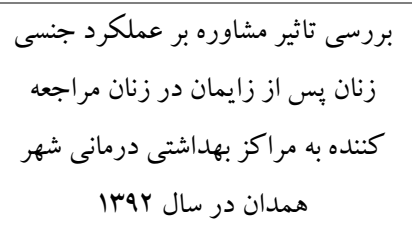 & ، حزبيانهوبا & $\begin{array}{l}r \\
1\end{array}$ \\
\hline 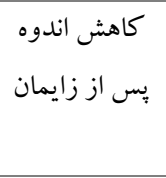 & تكر آموزش مر اقبت اغوشى در يك جلسه و & 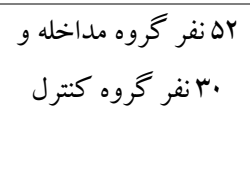 & 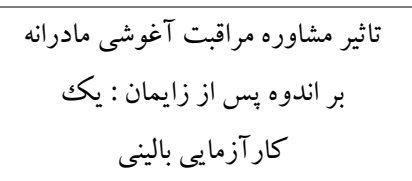 & شبيرى همدارا، & $r$ \\
\hline عزبود نمره & حل مسئله و ارام سازى در 9 جلسه بعد از & 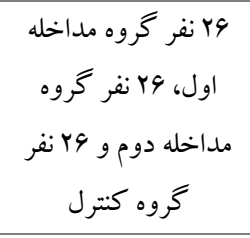 & مازيس اثر مهارت حل مسئله و آرام & نصيرى10 مشهد، & $r$ \\
\hline انحصبود تغذيه & 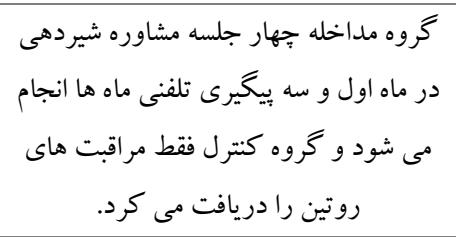 & 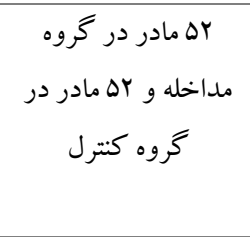 & 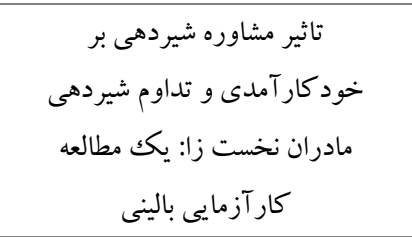 & هارساعqجا، & $\begin{array}{l}r \\
\varepsilon\end{array}$ \\
\hline جنهبود عملكرد & دريافت مشاورهبراساس مدل PLISSIT & 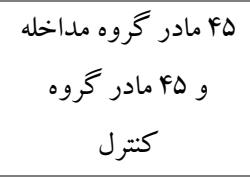 & 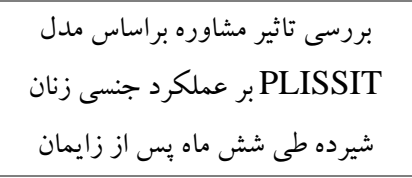 & ز زهر انى كهوسا & $\begin{array}{l}r \\
0\end{array}$ \\
\hline 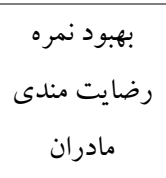 & درم افزار جند رسانه اى و كتاب آموزشى زنان در بيمارستان به مادران داده & 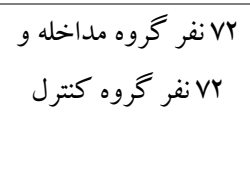 & مقايسه تاثير آموزش الكترونيك و & ريزى اوحمدى اصفهان & $\begin{array}{l}r \\
r\end{array}$ \\
\hline زايمان & 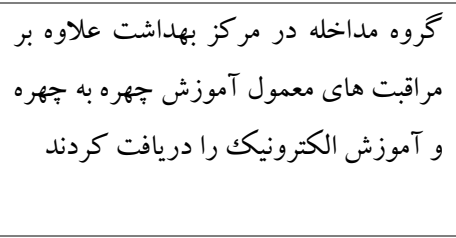 & 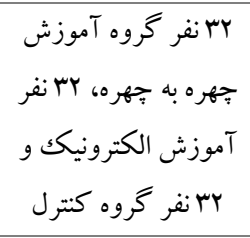 & 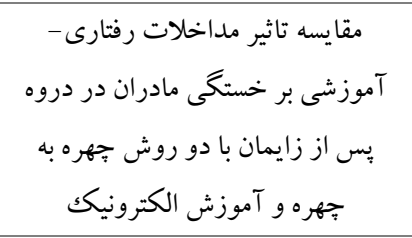 & 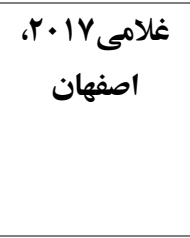 & $r$ \\
\hline 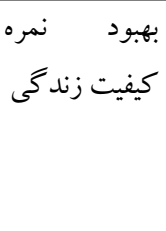 & 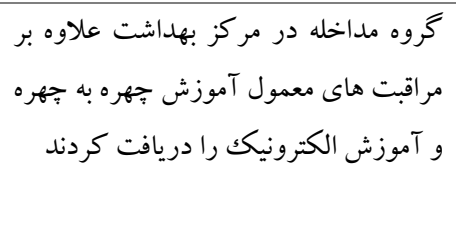 & 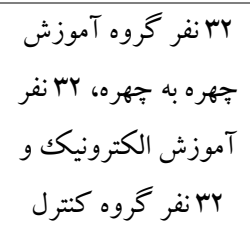 & 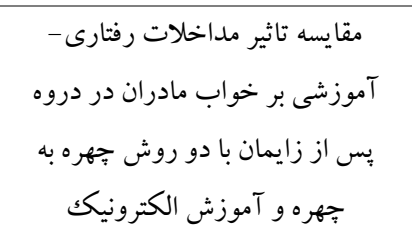 & غلامى11/ · r اصفهان & r \\
\hline بهبود نمره & يكك گروه بسته آموزش الكترونيكك به & 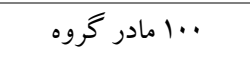 & بررسى تاثير بسته آموزش الكترونيك & سهرابى عqr| & $r$ \\
\hline
\end{tabular}




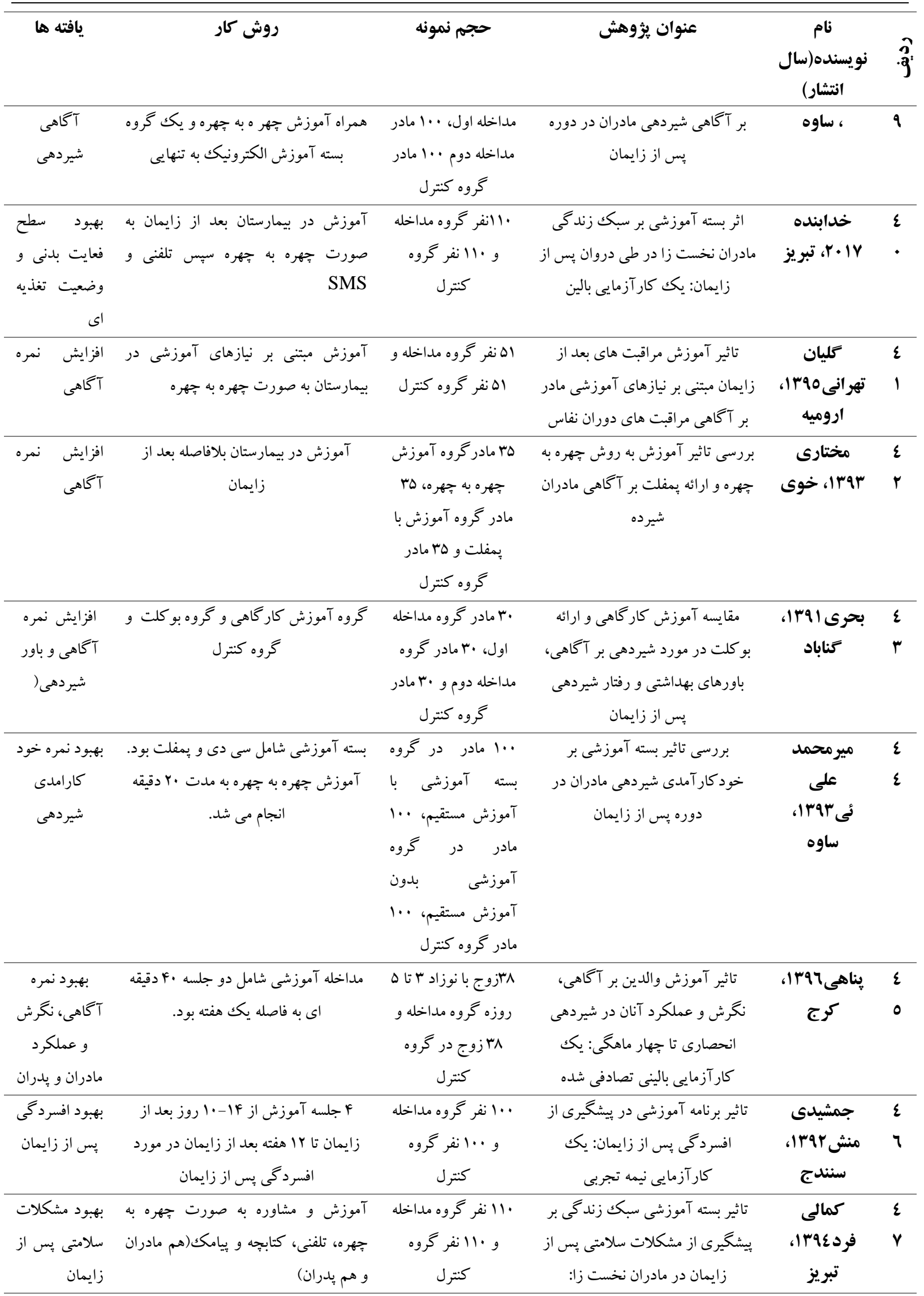




\begin{tabular}{|c|c|c|c|c|c|}
\hline يافته ها & روش كار & حجم نمونه & عنوان بُوهش & نويسنده(سال & \\
\hline & & & كار آزمايى بالينى تصادفى كنترل شده & & \\
\hline 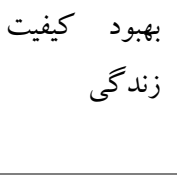 & دوره باردارى يره ناتال گروهى در ^ جلسه در & 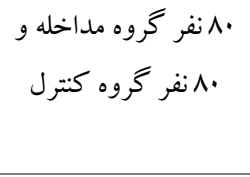 & 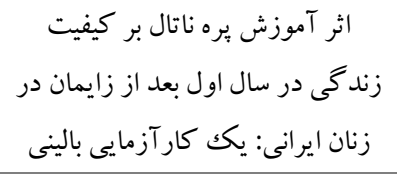 & 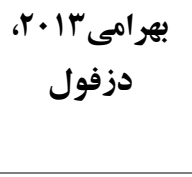 & $\wedge$ \\
\hline 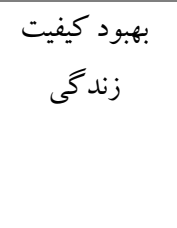 & شُهم بعد از زايمان اموزش در هفته هاى اول تا & و 4r نفر گروه مداخله و & 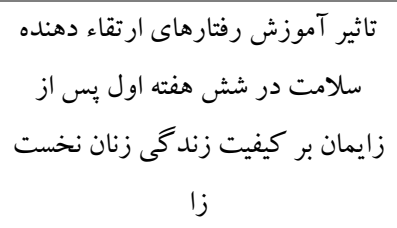 & قين اوس|ا، & \\
\hline
\end{tabular}

از زايمان برنامهاى را تدوين نموده است كه شامل سه نوبـت مر اقبتهــاى بـس از زايمـان كـه در مراكـز بهداشـى ارائسه مى شود. ما در اين مطالعه مرورى به مداخلات در زمينه يـس

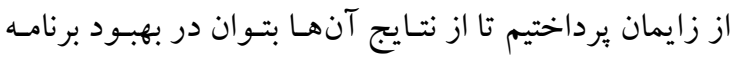

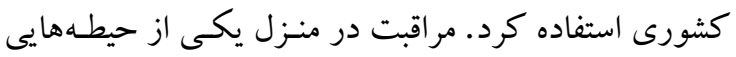

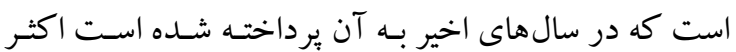

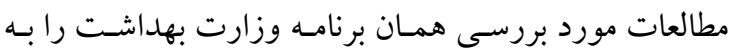

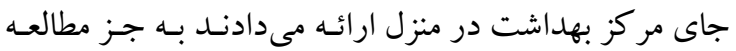
شمشيرى ميلانى كه يكك مطالعه تطبيقى نيـز انجام داده بـود

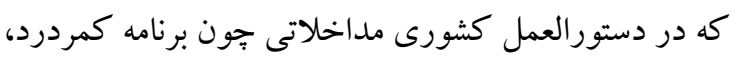
برخورد با هموروئيد، افسردگى بس از زايمان را اضافه كرده

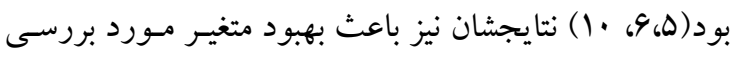
بود. به نظر مىرسد مراقبت در منزل بـه خـاطر صرف زمـان

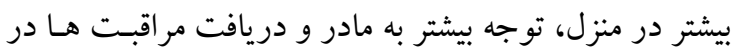

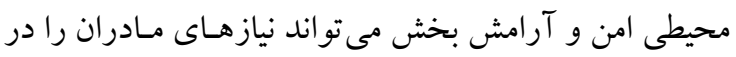

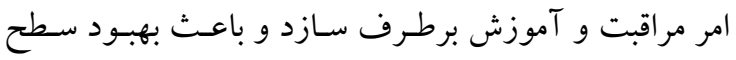

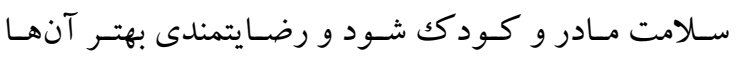

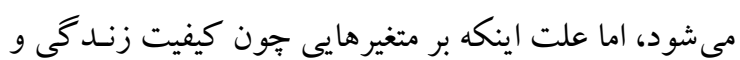

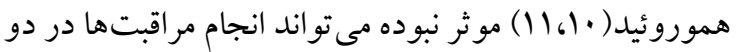

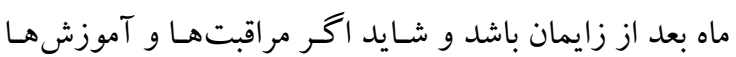
ادامه يابد بر بهبود اين متغيرها مـوثر باشـــ تئورىهـاى مـورد

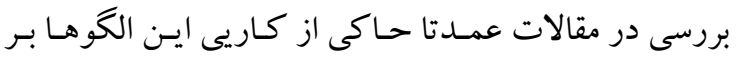

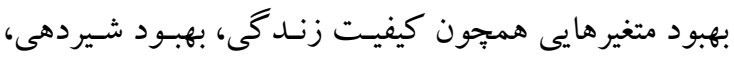

نتايج q4 مقاله مورد بررسى نشـان داد كـه مراقبـت در منـزل مى تواند با بهبـود رضـايت و عملكـرد مـادران در مراقبـت از خود و نوزاد، افسردگى پِ از زايمان و شيردهى شود اما بر كيفيت زندگى و بهبود هموروئيد و كمردرد موثر نمىباشد. همجنين حمايتهاى بعد از زايمان باعـث بهبود شيردهى و

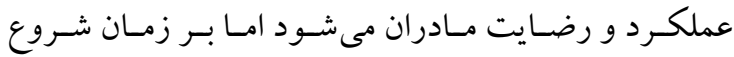
شيردهى موثر نمىباشد همجنين بـر روى افسردگى يـس از

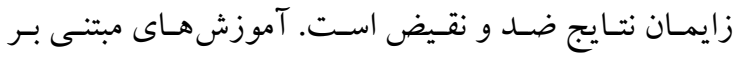

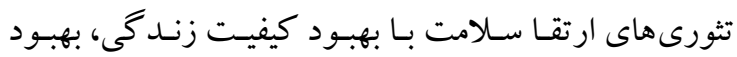

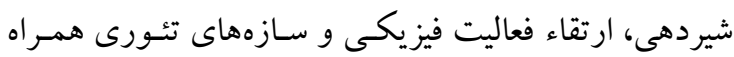

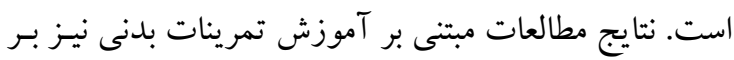

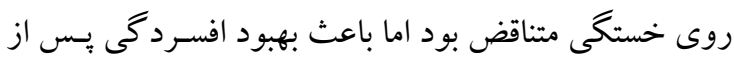

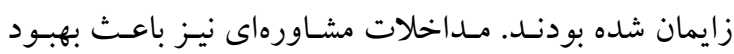

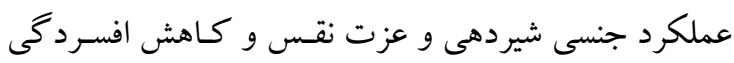

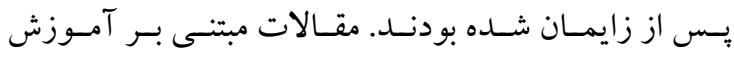

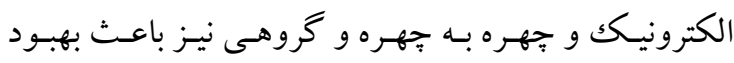
رضايتمندى، خستكى، خواب، شيردهى، عملكرد مـادران،

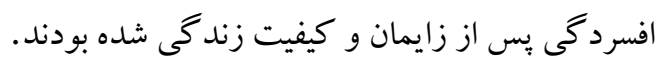

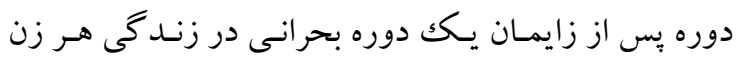
مىباشد كه از ديرباز مورد توجه بوده است ايسن دوره شـامل

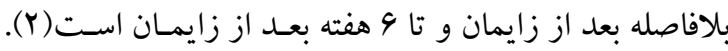
وزارت بهداشت، درمان و آموزش يز شكى بـراى دوره بـس بـ بـ نيس 


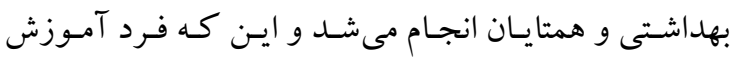

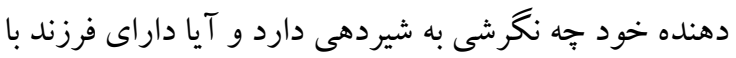

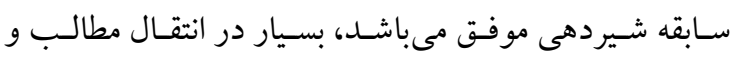

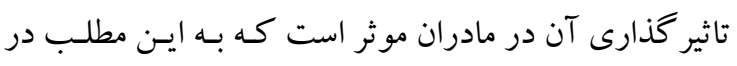

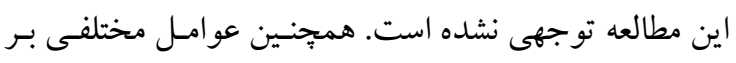

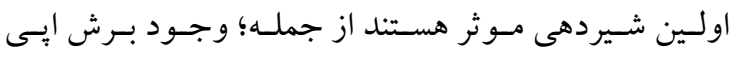

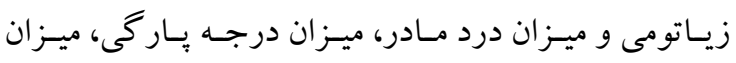
خستگىى مادر، مدت زمانى كه مادر درد كشيده است، آبِكار

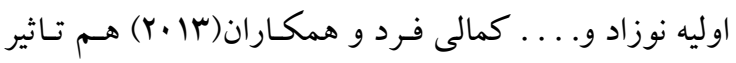

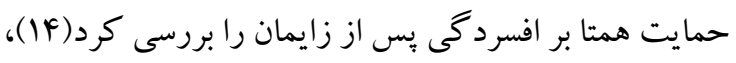

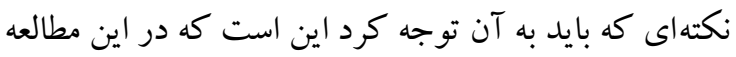

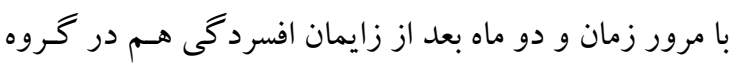

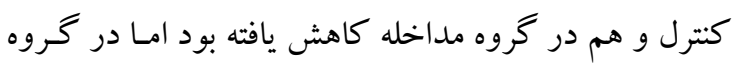
مداخله ميزان كاهش بيشتر بود. حمايتهاى تلفنى نيز باعـث دره

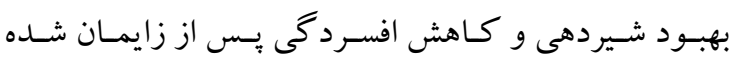

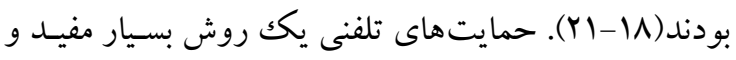
ارزان هستند كه باعث صرفه جويى اقتصادى و كاهش بـار كارى سيستم بهداشتى مىشود.

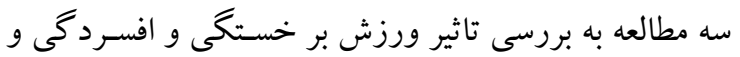

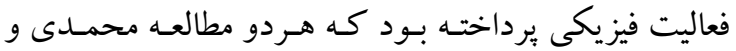

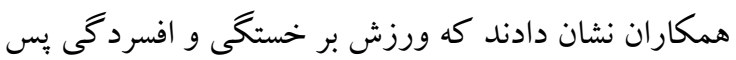

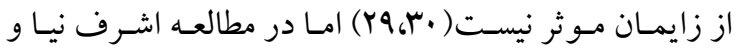
همكـارانش ورزش بـر خسـتخى و فعاليـت فيزيكسى مـوثر

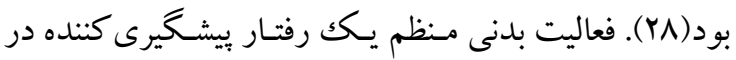

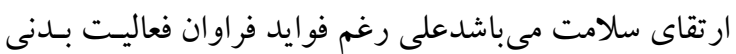
مطالعات در ايران نشان مىدهد كه بيش از •Vدرصـد افراد به اندازه كافى ورزش نمى كنند و اين درصد در زنان بِ از از

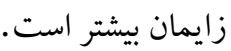
زنان بعد از زايمان نسبت به قبل از آن و مادران داراى فرزند نسبت به زنان بدون فرزنـد فعاليـت جسمانى كمترى انجـام

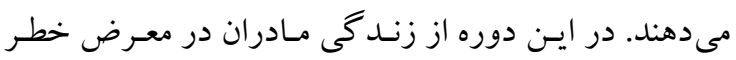

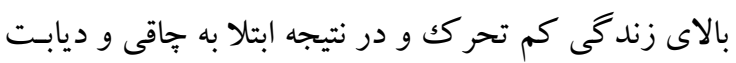

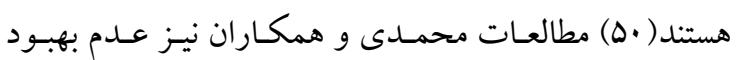

ارتقاى فعاليت فيزيكى بودند. تئورى خود مر اقبتى اورم بيـان

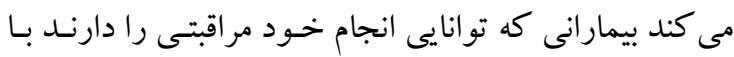

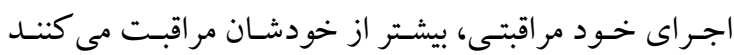

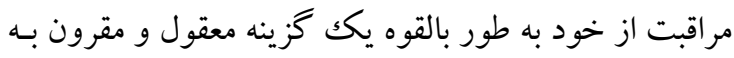

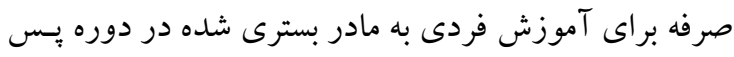

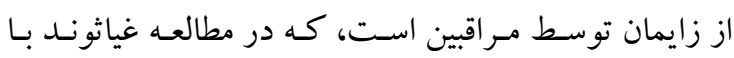

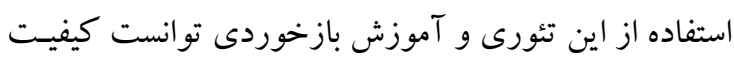

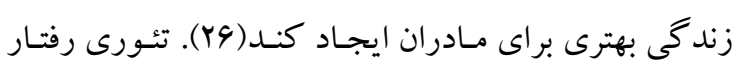

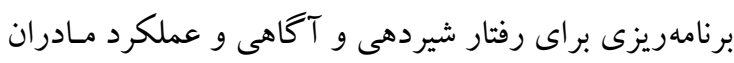

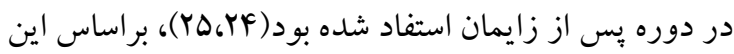
تئورى زمانى مادر قصد شيردهى رادارد، ديد مثبتى نسبت به

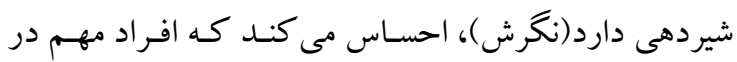

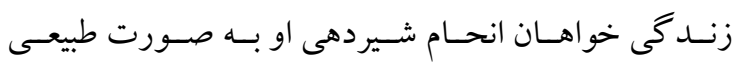

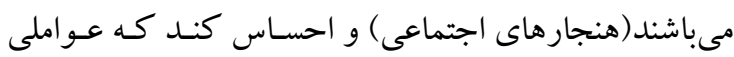

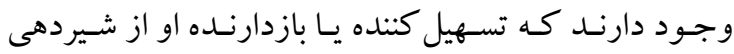
هستند ولى با وجود ايـن عوامـل او قـادر بـه شـيردهى موفق لق

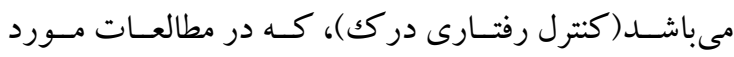
بررسى مادران شيردهى موفقى داشتند. براساس مــدل اعتقـاد

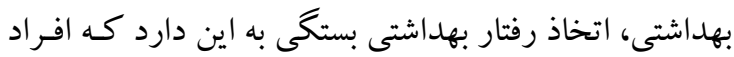

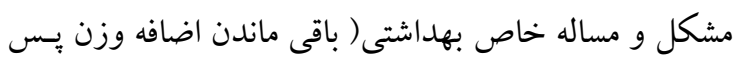

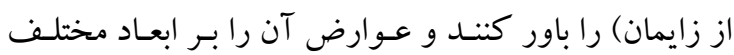

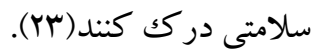
در حيطه الكوهاى حمايتى بدين صورت بـود كـه الكوهـاى

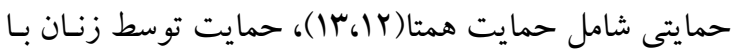
سابقه شيردهى موفق(YY)، حمايت خـانو اده محسور (IV-IV)

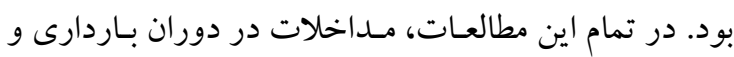

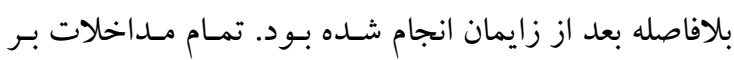

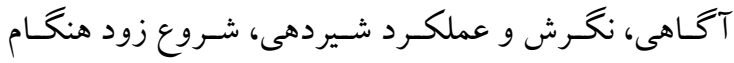

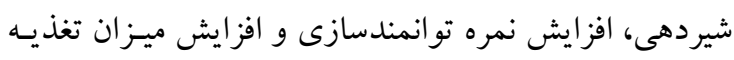

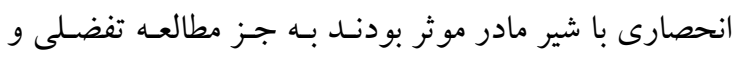

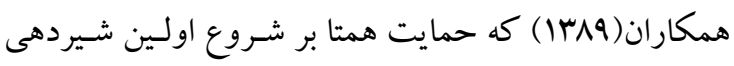

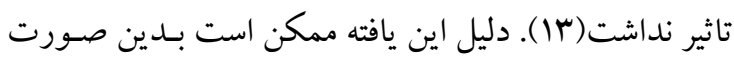

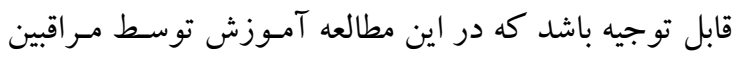


مراقبتهاى دو ران نفاس، عملكرد مادران، افسردگى بِ از

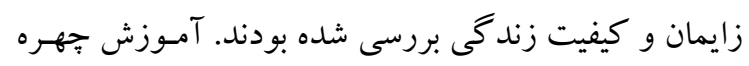

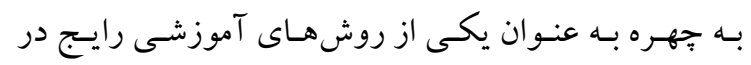

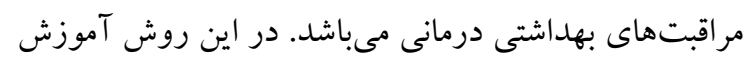

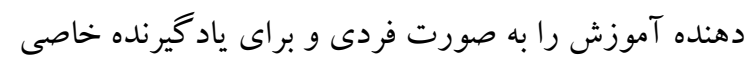

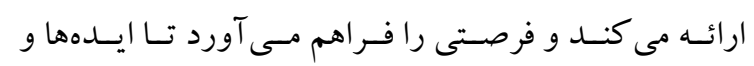

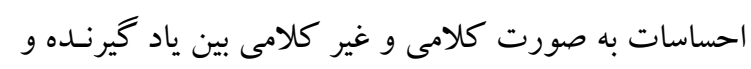
ياد دهنده تبادل گردد.

\section{نتيجه كيرى}

مداخلات اموزشى، در غالب طراحى بستهاى آموزشى بـــ

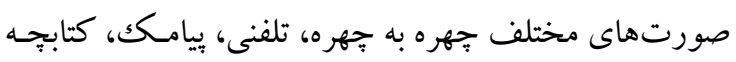

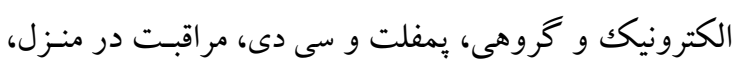
مشاوره و حمايت در دوران باردارى و بـس از زايمـان ارائسه

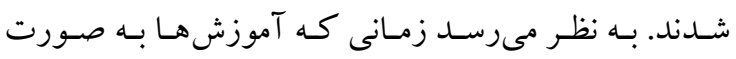

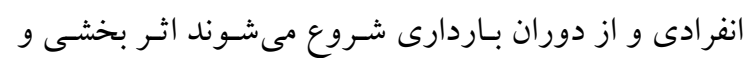
ماندكارى بيشترى خواهد داشت.

\section{تشكر و قدردانى}

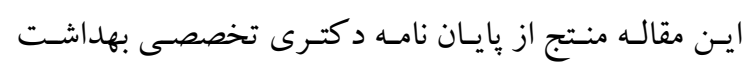

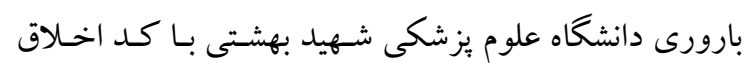

IR.SBMU.PHARMACY.REC.1398.089

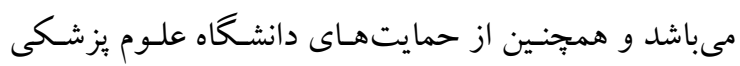

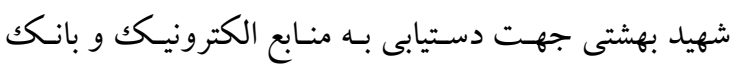
اطلاعاتى تشكر و قدردانى مىشود. هيج كدام از نويسند كان

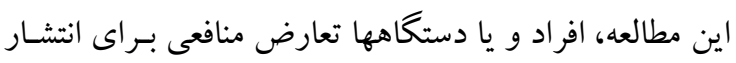

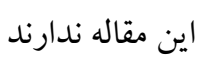

خستخى و افسردگى بس از زايمان رادر مطالعه خـود عـدم

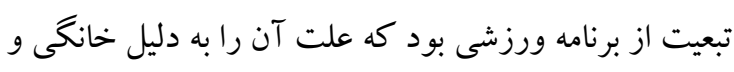

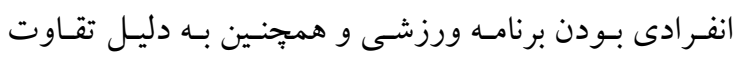

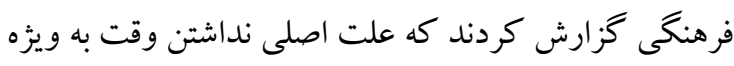

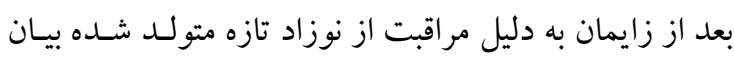
شد. آموزش الكترونيكك شـامل نرمافزار جنـــ رسانهاى، كتـاب

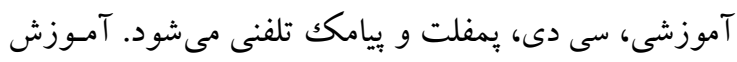

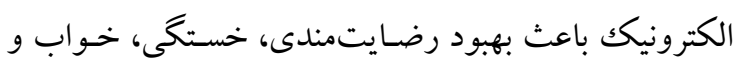

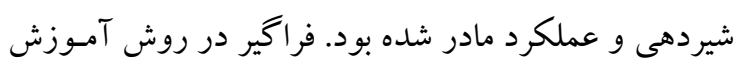
الكترونيكك مى تواند مطلب آموزشى را بدون آموزش جهردهره

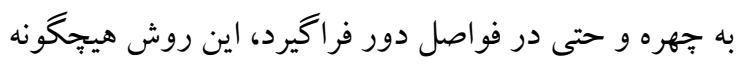

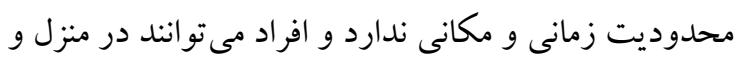

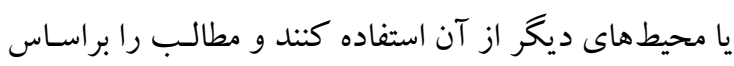
جدول زمانبندى ياد گيرى خود تنظيم نمايند.

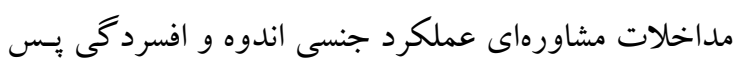

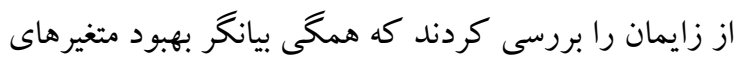

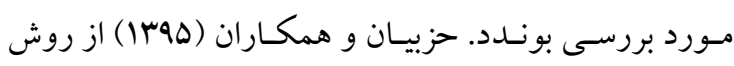

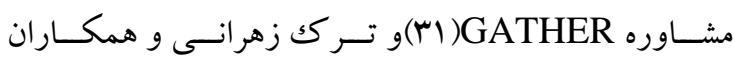

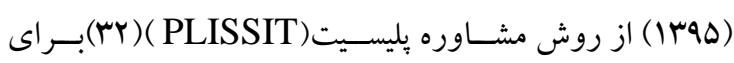

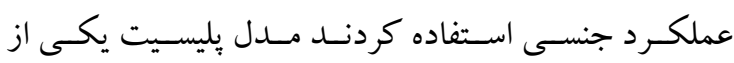
ير كاربردترين مدلها در زمينه ارزيابى و مشاوره جنسى است

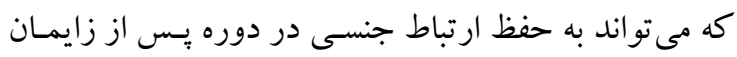
نيز موثر باشد. GATHER روش مشاورهاى است كه بيشتر بـراى مشـاوره تنظيم خـانو اده استفاده شـده كـه در مطالعه. جزيبان براى مشاوره جنسى در F جلسه انجام شد (اسم). مداخلات آموزشى به صورت جهره به جهره و گروهـى نيسز

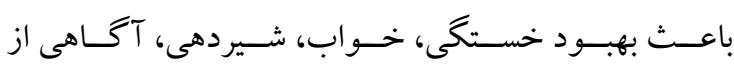

\section{منابع}

1- Mirmolaei T, AmelValizadeh M, Mahmoodi M, tavakol Z. The effect of postpartum home care on the level of maternal care and satisfaction. Evid Based Care J. 2011;1(1):36-50.(persian)

2- Mirmolaei T, AmelValizadeh M, Mahmoodi M, tavakol Z. The effect of postpartum home care on maternal practices in infant care. J UrmiaNurs Midwifery Fac. 2012;10(3).(persian)

هبله علمى دانشكاه علوه يِشكى كردستان / دوره بيست و شش / درداد و شهريور م.ع|| 
3- Mirmolaei ST, AmelValizadeh M, Mahmoodi M, Tavakol Z. Comparison of effects of home visits and routine postpartum care on the healthy behaviors of Iranian low-risk mothers. Int J Prev Med. 2014;5(1):61-68.

4-Mokhtari F, Bahadoran P, Baghersad Z. Effectiveness of postpartum homecare program as a new method on mothers' knowledge about the health of the mother and the infant. Iranian $\mathrm{J}$ Nursing Midwifery Res. 2018;23:316-21.

5- Milani HS, Amiri P, Mohseny M, Abadi A, Vaziri SM, Vejdani M. Postpartum home care and its effects on mothers' health: A clinical trial. J Res Med Sci. 2017;22:96.

6- Milani HS, Amiri P, Mohseny M, Abadi A, Vaziri SM, Vejdani M. Effect of Health Care as the "Home Visiting" on Postpartum Depression: A Controlled Clinical Trial. Int J Prev Med. 2017;8:20.

7- Sakaki M, DaneshKajori M, KHeyrkhah M, Hoseini Agha F. The Effect of Home Visit after Cesarean Delivery on Exclusive Breastfeeding in Neonatal Period. IJN. 2010;23(64):72-80.(Persian)

8- Mohseni H, Jahanbin I, Sekhavati E, Tabrizi R, Kaviani M, Ghodsbin F. An Investigation Into the Effects of Prenatal Care Instruction at Home on Breast-Feeding Self-Efficacy of First-Time Pregnant Women Referred to Shiraz Clinics. IJWHR. 2018:6(1):41-46

9- Mojalli M, BasiriMoghadam M, Shamshiri M. Effectiveness of Instructional Environment and Related Factors on Breastfeeding Function of Mothers. Horizon Med Sci. 2010;16 (1):59-64.(Persian).

10- Milani HS, Amiri P, Heidarnia MA, Abachizadeh K, Abadi A, Malekkhahi A. The Effects of Postpartum Home Care on Constipation and Hemorrhoids at Sixty Days Postpartum. J BabolUniv Med Sci. 2015;17(12):26-32(Persian)

11- Mirmolaei T, AmelValizadeh M, Mahmoodi M, tavakol Z. The effect of postpartum home care on the quality of life of mothers with low risk . Hayat. 2011;17(2):42-51(persian)

12- Moudi A, Tafazoli M, Boskabadi H, Ebrahimzadeh S, Salehiniya H. Comparing the Effects of Peer Support and Training by Healthcare Providers on Primiparous Women's Breastfeeding SelfEfficacy. J Midwif Reprod Health. 2016;4(1):488-497(Persian)

13-Tafazzoli M. moudi A, Boskabadi H, EbrahimzadehS. Comparing the Effect of Peer Support and the Education of Health Care Providers on Breastfeeding Initiation Time among Primiparous Women in Mashhad. Iran J Obstet Gynecol Infertil. 2012;15(4):19-28

14- Kamalifard M, Yavarikia P, Babapour Kheiroddin J, Salehi Pourmehr H, Iraji Iranagh R. The effect of peers support on postpartum depression: a single-blind randomized clinical trial. J Caring Sci. 2013;2(3):237-244.

15- Heidari Z, Keshvari M. Clinical trial to comparison the Effect of Family- centered Educationalsupportive Program on Mothers' Empowerment in Breast-feeding. Int J Pediatr. 2016;4(3):1445-51.

16- Heidari B, Etemadifar S, Raiss M. Effect of implementing an educational support program on lactation and performance information Mothers referring to health centers in Shahr-e-Kord. J Clin Nurs Midwifery. 2016;5(1):67-75(Persian).

17- Kohan Sh ,Heidari Z. Promoting breastfeeding empowerment in primiparus women: effect of family-center education and support. Daneshvar Med. 2016;24(125):51-58(Persian)

18- Raisi Dehkordi Z, Raei M, GhassabShirazi M, RaisiDehkordi SAR, Mirmohammadali M. Effect of Telephone Counseling on Continuity and Duration of Breastfeeding among Primiparus Women. Hayat. 2012;18(2):57-65(Persian)

19- Shamshiri Milani H, Azargashb E, Beyraghi N, Defaie S, Asbaghi T. Effect of telephone-based support on postpartum depression: a randomized controlled trial. Int J FertilSteril. 2015;9(2):247-253.

20- Mohammad-Alizadeh-Charandabi S, Malakoti J, Sohrabi F, Shokranian N. The effect of telephone support on postpartum depression: a randomized controlled trial. J Caring Sci. 2013;2(2):147-155.

21- Peighambardost R, Fadaiy Z. Effect of Telephone support and Women satisfaction of Postpartum care. J Clin Nurs Midwifery. 2016;5 (1):36-46.

22- TorkZahrani S, Karamollahi Z, Azgoli G, AkbarpurBaghian A, Sheikhan Z. Effect of Support from the Mothers with Positive Breast Feeding Experience on Breast Feeding Pattern and Duration among Primiparous Women Referred to MaternityWard of Ilam Hospital, 2010 . sjimu. 2012;20(2):916.(Persian)

هجله علهى دانشكاه علوه دِزشكى كردستان / دوره بيست و شش / درداد و شهريور م.ع|| 
23- Safarzadez S, Behboodi Moghaddam Z, Saffari M. The Impact of Education on Performing Postpartum Exercise Based on Health Belief Model. Iran J Med Phys. 2014;6(57):776-784(Persian).

24- Ahmadi M, Jahanara S, Moeini B, Nasiri M. Impact of Educational Program Based on the Theory of Planned Behavior on Primiparous Pregnant Women's Knowledge and Behaviors Regarding Breast Feeding. JHC. 2014;16(1):19-31.

25- Keramat A, Masoumi SZ, Shobeiri F, Raei M, Andarzgoo M, Babazadeh R. Effectiveness of educational program related to persuade women for breast feeding based on theory of planned behavior (TPB). Sci J Hamadan Nurs Midwifery Fac. 2013;21(2):21-31.

26- Ghiasvand F, Riazi H, Hajian S, Kazemi E, Firoozi A. The effect of a self-care program based on the teach back method on the postpartum quality of life. Electron Physician. 2017;9(4):4180-4189

27- Abdeyazdan Z, Elahi T, Golshiri P. Comparison of an empowering breastfeeding program before and after childbirth on exclusive breastfeeding time span. Mod Care J. 2015;11(4):330-338(persian).

28- Ashrafinia F, Mirmohammadali M, Rajabi H, Kazemnejad A, SadeghniiatHaghighi K, Amelvalizadeh M. Effect of Pilates exercises on postpartum maternal fatigue. Singapore Med J. 2015;56(3):169-73.

29- Mohammadi F, Malakouti J, Mohammad Alizadeh S, Babapoor J. The Effect of Exercise on Postnatal Fatigue: A Controlled Clinical Trial. Iran J Obstet Gynecol Infertil. 2013;16(71):7-13.

30- Mohammadi F, Malakooti J, Babapoor J, Mohammad-Alizadeh-Charandabi S. The effect of a home-based exercise intervention on postnatal depression and fatigue: A randomized controlled trial. Int J NursPract. 2015;21(5):478-85.

31- Hezbiiyan Z, Khodakarami B, Parsa P, Faradmal M J. The effect of postnatal counseling on sexual function in women referred to health centers in Hamedan in 1392. Avicenna J Nurs Midwifery care. 2016;24(4):272-280.

32- Torkzahrani S, Banaei M, Ozgoli G, Azad M, Mahmoudikohani F. THE Effectivenessof consultation based on plissit model on sexual function of lactating women. J UrmiaNurs Midwifery Fac. 2016;14(7):639-647.

33- Shobeiri F, Hajian S, Massoumi Z, Soltanian A. The Effect of Kangaroo Mother Care Counseling on Postpartum Blues, A Randomized Clinical Trial. Sci J Hamadan Nurs Midwifery Fac. 2018;26(2):113-119(Persian).

34- Parsa P, Boojar A, Roshanaei G, Bakht R. The Effect breastfeeding counseling on self-efficacy and continuation breastfeeding among primiparous mothers: a randomised clinical trial. Sci $\mathrm{J}$ Hamadan Nurs Midwifery Fac. 2016;24(2).(Persian)

35- Nasiri S, Kordi M, Gharavi MM. A comparative study of the effects of problem-solving skills training and relaxation on the score of self-esteem in women with postpartum depression. Iran J Nurs Midwifery Res. 2015;20(1):105-112.

36- Khodabandeh F, Mirghafourvand M, KamaliFard M, Mohammad-Alizadeh-Charandabi S, AsghariJafarabadi M. Effect of educational package on lifestyle of primiparous mothers during postpartum period: a randomized controlled clinical trial. Health Educ Res. 2017;32(5):399-411

37- Mohamadiriz S, Bahadoran P, Fahami F. Comparison between the Impacts of E-Learning and Booklet Education on Nulliparous Women's Satisfaction about Postpartum Care. IJOGI. 2013;16(61):1-8.

38- Gholami Z, Mohammadirizi S, Bahadoran P. Study of the impact of educational behavioral interventions on fatigue in mothers in the postpartum period in the groups of face-to-face and electronic training. Iranian J Nursing Midwifery Res. 2017;22:465-70.

39- Gholami Z, Bahadoran P. Comparing the impact of educational behavioral interventions on maternal sleep between face-to-face and electronic training groups, during the postpartum period. $\mathbf{J}$ Educ Health Promot. 2018 2;7:107.

40- Sohrabi Z, Sohrabi N, Hashemzade M, Mehran A, Mir mihamadaliei M. An Evaluation of the Effect of Electronic Education on Breastfeeding Knowledge in the Postpartum Period. J Health Syst Res. 2016;11(4) :741-746(Persian). 
41- Mir mihamadaliei M, Sohrabi Z, Sohrabi N, Hashemzade M, Mehran A. The effect of educational package on the self-efficacy of breast feeding in postpartum period. Payesh Health monit. 2014;13(2):221-228(Persian).

42- Mokhtary L, KhoramiMarekani A, Habibpoor Z. The effect of face to face education and pamphlet giving on knowledge of mothers about breast feeding. J UrmiaNurs Midwifery Fac. 2014;12(9):825832

43- Bahri N, Bagheri S, Erfani M, Rahmani R, Tolidehi H. The Comparison of Workshop-Training and Booklet-Offering on Knowledge, Health Beliefs and Behavior of Breastfeeding after Delivery. Iran J Obstet Gynecol Infertil. 2012;15(32):14-22(Persian).

44-Kamalifard M, Mirghafourvand M, Mohammad alizadecharandabi S, Khodabandeh F, AsghariJafarAbadi M, Mansoori A. Effect of Lifestyle Educational Package on Prevention of Postpartum Health Problems in Nulliparous Mothers: A RandomizedClinical Trial. J MazandaranUniv Med Sci. 2015;25(132):33-48(Persian).

45- GolyanTehrani S, NeisaniSamani L, RahimiForoushani A, Ebrahimi M, karimi n. Evaluation of effect of postpartum care education based on maternal educational needs on knowledge of postpartum care. J UrmiaNurs Midwifery Fac. 2017;15(2):76-85(Persian).

46- Jamshidimanesh M, GolianTehrani Sh, Hosseini F, Narges Shams Alizadeh, ForouzanLahoni. The effect of an educational program on prevention of postpartum depression. Payesh Health monit. 2013; 12(6):619-627(Persian).

47- Panahi F. Simbar M. Study of effect of training parents on their knowledge, theory and action and pattern of breastfeeding until four month. IJOGI. 2017;20(5):48-57(Persian).

48- Ghodsbin F, Yazdani K, Jahanbin, Keshavarzi. The Effect of Education on Health-Promoting Behaviors at the First Six Weeks Post-delivery on the Quality of Life of Primiparous Women. Armaghane-danesh. Armaghane-danesh. 2012;17(2):279-289(Persian).

49- Bahrami N, Simbar M, Bahrami S. The effect of prenatal education on mother's quality of life during first year postpartum among iranian women: a randomized controlled trial. Int J FertilSteril. 2013;7(3):169-174(Persian).

50- Farshi M, Babatabar Darzi H, Mahmoudi H, Mokhtari Nouri J. Comparison of nursing care learning in air evacuation andtransport by lecture and e-learning methods. J Mil Med. 2012;14(1):2731(Persian). 